\title{
Intorme sobre evaluación de la calidad de las Universidades
}

\section{Consejo de Universidades}

\section{Introducción}

A iniciativa del Consejo de Universidades ${ }^{1}$ y a propuesta del Ministro de Educación, el Gobierno acordó mediante Real Decreto de 1 de diciembre de 1995 establecer el Plan Nacional de Evaluación de la Calidad de las Universidades ${ }^{2}$, que se ejecutará a través de convocatorias anuales.

La primera convocatoria, a propuesta del Consejo de Universidades ${ }^{3}$, se realizó por el Ministro de Educación mediante Orden de 21 de febrero de $1996^{4}$ y a propuesta del Secretario General del Consejo de Universidades, oído el Comité Técnico del Plan ${ }^{5}$, se resolvió por Orden de la Ministra de Educación y Cultura de 30 de octubre de $1996^{6}$.

El artículo 5 del citado Real Decreto establece que el Consejo de Universidades elaborará un informe anual, cuya propuesta según señala el artículo 7, corresponde al Secretario General del Consejo de Universidades.

Por otra parte, el apartado duodécimo de la Orden de la primera convocatoria del Plan establece que la estructura organizativa necesaria para su ejecución se desarrollará conforme a lo previsto en el acuerdo del Pleno del Consejo de Universidades, en su sesión de 25 de septiembre de 1995.

En dicho acuerdo se señala que corresponde al Pleno del Consejo de Universidades, entre otras competencias referidas al Plan Nacional, realizar el control y seguimiento de su ejecución y aprobar un informe anual sobre la calidad de las Universidades en el que se reflejen, globalmente, los resultados del Programa de Evaluación?

El Consejo de Universidades en su sesión de 4 de julio de 1996, celebrada en Alicante, constituyó la Comisión Ejecutiva del Plan Nacional de Evaluación ${ }^{8}$, a la que corresponde el seguimiento del Plan e informar las resoluciones que se sometan a la aprobación del Pleno.

El apartado octavo de la referida Orden de convocatoria de 1996 señala que la duración de los proyectos anuales de evaluación es de un año desde la concesión de la financiación del proyecto.

Transcurrido un año desde la concesión de la financiación para la realización de los proyectos de evaluación, a propuesta del Secretario General, el Pleno del Consejo de Universidades, en su sesión celebrada en Madrid el 18 de diciembre de 1997, acordó el presente INFORME SOBRE EL PLAN NACIONAL DE EVALUACIÓN DE LA CALIDAD DE LA UNIVERSIDADES.

\section{El Plan Nacional de Evaluación}

En este capitulo se describen los objetivos del Plan Nacional de Evaluación de la Calidad de la Universidades, los principales rasgos del método de evaluación, se bace balance de las actividades realizadas y se formula una valoración del proceso desarrollado en la primera convocatoria.

El Plan Nacional de Evaluación de la Calidad de la Universidades, tras las experiencias del Programa Experimental de Evaluación de la Calidad del Sistema Universitario ${ }^{9}$ y del Proyecto Piloto de Evaluación de la Enseñanza Superior de la Unión Europea ${ }^{10}$, persigue cumplir los siguientes objetivos: 
1. Promover la evaluación institucional de la calidad de las Universidades en los ámbitos de la enseñanza, la investigación y los servicios prestados a la sociedad.

2. Facilitar a las Universidades y a las administraciones educativas un método homogéneo y unos criterios básicos comunes para la evaluación, compatibles con la práctica vigente en la Unión Europea.

3. Proporcionar a la sociedad, especialmente a los estudiantes universitarios actuales o potenciales, información relevante y objetiva sobre la calidad de las Universidades españolas.

4. Proporcionar a las administraciones educativas y al Consejo de Universidades una información objetiva sobre el nivel de calidad alcanzado que pueda servir de base para la adopción de decisiones en el ámbito de las respectivas competencias.

Para desarrollar tales objetivos el Plan Nacional adoptó los siguientes criterios.

\section{Orientación a la mejora de lacalidad}

El proceso de evaluación persigue facilitar el desarrollo de acciones concretas para mejorar la calidad de la Universidad y no está vinculado directamente ni a consecuencias relacionadas con la financiación ni a procesos de acreditación administrativos.

Esta orientación justifica que se escogiera el programa de formación (la titulación) y el Departamento como el ámbito institucional objeto de evaluación, dado que para el usuario (alumno o empleador) el único referente es la titulación y para el profesor es el departamento su referencia organizativa más directa.

Sin perjuicio de ello, la difusión de los resultados de la evaluación servirá también para un mejor conocimiento, por la sociedad, de los niveles de calidad alcanzados por cada Universidad.

Igualmente las Administraciones Educativas podrán considerar los resultados de los proyectos de evaluación para diseñar sus planes de actuación en materia universitaria.

\section{Participación voluntaria de las Universidades}

Dado que gran parte de las Universidades están en un período de consolidación, no parecía posible fomentar una cultura de evaluación y de mejora de la calidad bajo la presión directa de la participación obligatoria y, en consonancia con la autonomía que la Constitución reconoce a la Universidad, se estable- ció un mecanismo de participación voluntaria, que prevé, además, la posibilidad de diferentes niveles de complejidad y ritmos de ejecución también distintos.

Para favorecer la necesaria homogeneidad de los procesos de evaluación, acelerar su implantación y sobre todo para garantizar los elementos de evaluación externa, el Plan incorporó una subvención finalista vinculada a la calidad de los proyectós de evaluación presentados por las Universidades.

\section{Coordinación del Plan}

El plan pretende aunar las competencias de las Comunidades Autónomas en materia de enseñanza superior con la adopción de un marco de referencia común para el conjunto del sistema universitario estableciendo instrumentos organizativos que aseguren tanto la presencia de las Comunidades Autónomas en los órganos colegiados de gestión del Plan, como la posibilidad de establecer fórmulas de gestión protagonizadas por las Comunidades Autónomas mediante técnicas de cooperación.

La necesidad de contar con instrumentos metodológicos comunes aconsejó que la coordinación del Plan correspondiera al Secretario General del Consejo de Universidades, apoyado por una Oficina de gestión y un Comité Técnico.

\section{Ámbito de la evaluación}

La evaluación se extiende, de forma comprensiva, a la enseñanza, la investigación y a la organización universitaria, en la línea ensayada en el Programa Experimental de Evaluación, desarrollado entre 1992 y 1994.

El Plan tiene una duración de cinco años, que debe permitir que la mayor parte de las titulaciones y departamentos de la Universidad española puedan integrarse en los procesos de evaluación.

\subsection{El Procedimiento de evaluación}

Las experiencias del Programa experimental y del Proyecto. Piloto Europeo han permitido adoptar un modelo de evaluación homologable al empleado en los sistemas universitarios intemacionales con más experiencia, que incorporan para cada titulación y departamento un proceso de revisión interna (autoevaluación) junto a otro de evaluación externa.

Por otra parte, la Comisión de la Unión Europea en su recomendación " al Consejo relativa a la cooperación europea en materia de garantía de la calidad en la enseñanza superior 
pone de manifiesto la necesidad de establecer mecanismos permanentes de evaluación y de garantía de la calidad que permitan evaluar los puntos fuertes y débiles de las instituciones de enseñanza superior en relación con los objetivos de las enseñanzas de cada Universidad, teniendo en cuenta sus características institucionales y las exigencias sobre formación a escala europea y mundial.

Y señala además que ala utilización de elementos metodológicos comunes no conduce a una clasificación jerárquica o a una norma común europea", sino por el contrario que "los métodos de evaluación de la calidad son reglas de procedimiento, pero no de contenido. Esto significa que definen el procedimiento de la evaluación de la calidad (quiénes participan en la misma, los aspectos que serán examinados, etc.)n, pero sin establecer qué criterios determinan la calidad de una institución.

La Guía de evaluación elaborada por el Comité Técnico del Plan abarca las tres dimensiones de la evaluación (Enseñanza, Investigación y Gestión), así como directrices sobre el método y organización (estructura y desarrollo) del proceso.

\section{Definición de las titulaciones objeto de evaluación}

El Plan no establece previamente qué Universidades ni qué titulaciones o departamentos deben evaluarse en cada una de la convocatorias, si no que opta por que sean las propias Universidades las que, al solicitar la financiación de un proyecto de evaluación concreto, determinen su alcance tanto por lo que se refiere a las titulaciones que se evaluarán, como por lo que respecta a la estructura organizativa y al método o en general al proceso de evaluación, siempre dentro de los márgenes establecidos en la Guía de evaluación que se configura como un instrumento metodológico común y no como un cuestionano para una revisión general de las características del sistema universitario.

\section{Revisión interna}

El proceso de evaluación se inicia con una fase de revisión interna, que se denomina autoevaluación, responsabilidad de cada Universidad. La Guía de evaluación recomienda constituir un Comité en cada una de las titulaciones objeto de evaluación cuya función es elaborar un informe, en el que tras describir los objetivos y la situación de cada unidad de evaluación, fijándose en la lista de comprobación que se recoge en la Guía, se valore, de acuerdo con el sentir mayoritario de la comunidad universitaria, las fortalezas y debilidades de la titulación y de los departamentos, señalando al tiempo propuestas concretas para mejorar la calidad.

\section{Evaluación externa}

Una segunda fase la constituye la evaluación externa, responsabilidad de la Secretaría General del Consejo de Universidades. La Guía de evaluación determina que cada unidad evaluada recibirá la visita de un Comité externo, seleccionado por el Consejo de Universidades, cuya función es analizar el autoestudio, contrastándolo con la información que obtiene al realizar sistemáticamente un conjunto de entrevistas semiestructuradas ( $\mathrm{Co}$ mité interno de evaluación, Equipos directivos, Profesorado, Personal de administración y servicios, Alumnos de primer y segundo ciclo, Graduados) y elaborar un informe de evaluación externa que valorará igualmente los objetivos, la situación, los puntos fuertes y débiles al tiempo que formulará recomendaciones para mejorar la calidad.

\section{Informe de Evaluación}

El proceso de evaluación concluye con la redacción, por el Comité de Evaluación de la Unidad Evaluada y en su caso de la Universidad, de un informe que integre los documentos generados en la autoevaluación y en la evaluación externa, señalando especialmente las decisiones que deberá tomar la institución a la luz de la evaluación realizada. Este informe o en todo caso sus aspectos sustantivos deberán hacerse públicos.

\section{Informe anual sobre la situación del Plan Nacional de Evaluación de la Calidad de las Universidades}

Un último elemento lo constituye el informe que anualmente deberá aprobar el Consejo de Universidades, cuya elaboración corresponde al Secretario General del Consejo de Universidades, que debe recoger globalmente los resultados del Plan.

\subsection{Balance de la primera convocatoria}

\subsubsection{Universidades participantes, tipos de proyectos $y$ calendario}

En la primera convocatoria del Plan Nacional de Evaluación (1996) participan 46 Universidades, públicas y privadas que presentaron 7 proyectos globales, 32 temáticos, y 31 acciones especiales para dotar a la Universidad de oficinas de evaluación. Se han evaluado 130 titulaciones.

El Ministerio de Educación y Cultura ha financiado la realización de los proyectos de evaluación con 184 millones de pesetas. 
El calendario previsto para cada una de las fases del proceso de evaluación se estructura conforme al siguiente esquema:

1. Fase de autoevaluación: 5 meses.

2. Fase de evaluación extërna: 3 meses.

3. Redacción y aprobación del informe de evaluación: 2 meses.

4. Difusión de los resultados: 2 meses.

El cómputo de estos plazos se inicia el 8 de noviembre de 1996, fecha de la publicación en el Boletín Oficial del Estado de la concesión de la financiación. Sin embargo, algunas Universidades no empezaron las actividades relacionadas con el Plan de Evaluación hasta la efectiva transferencia de las subvenciones previstas en la citada Orden.

\subsubsection{Actividades realizadas por la Secretaria General del Consejo de Universidades}

El acuerdo del Consejo de Universidades de 25 de septiembre de 1995, recogido en el Real Decreto 1947/1995, de 1 de diciembre, encomienda al Secretario General del Consejo de Universidades la gestión y coordinación del Plan Nacional de Evaluación, para lo cual contará con la asistencia de un Comité Técnico.

Para atender al Secretario General en las tareas derivadas de la coordinación y gestión del Plan, el Consejo de Universidades propuso crear, en la Secretaría General, una Oficina de gestión de evaluación de la calidad de las Universidades, dotada de personal cualificado para las tareas de evaluación, dirigida por un Vicesecretario del Consejo.

Sin embargo, hasta la fecha, no ha sido creada la Oficina de Gestión prevista en el Plan Nacional de Evaluación. Para facilitar su gestión, el Secretario General del Consejo de Universidades encomendó a la Vicesecretaría de Estudios, en enero de 1996, desarrollar las funciones previstas para la Oficina de Gestión, sin que hasta el momento al Consejo de Universidades se hayan incorporado los medios personales y materiales previstos en la Disposición final segunda del mencionado Real Decreto para el desarrollo del Plan Nacional.

Desde la aprobación del Plan Nacional la Secretaría General del Consejo de Universidades ha desarrollado las siguientes actividades:

\section{Constitución del Comité Técnico}

El Comité Técnico ${ }^{12}$ se constituyó en la sede del Rectorado de la Universidad Politécnica de Cataluña el 15 de marzo de 1996 y le corresponden las siguientes funciones:
1. Aprobar los protocolos, guías y normas técnicas para la evaluación de la calidad de las Universidades.

2. Evaluar la calidad y viabilidad de los proyectos presentados por las Universidades.

3. Organizar la formación y preparación de evaluadores de las Universidades.

4. Nombrar a los evaluadores externos que participen en cada proyecto.

5. Aprobar un informe sobre cada proyecto de evaluación.

6. Colaborar con el Secretario General en la elaboración de un informe anual sobre la calidad de las Universidades, que será sometido a dictamen de la Comisión de seguimiento para su aprobación en el Pleno del Consejo de Universidades.

7. Asesorar al Secretario General en todos los temas relacionados con el Programa Nacional de Evaluación Institucional de la Calidad de las Universidades.

Desde su constitución ha celebrado 7 sesiones ${ }^{13}$ plenarias y 36 sesiones de los grupos de trabajo acordados en la constitución del Comité Técnico.

Elaboración de la documentación técnica

El Comité Técnico del Plan ha elaborado la documentación técnica necesaria para desarrollar el proceso de evaluación integrada por los siguientes documentos:

1. Guía de evaluación.

2. Guía de evaluadores externos.

3. Material para la sesiones de formación de los Comités de Evaluación.

Presentación de las características del Plan Nacional de Evaluación

Una vez seleccionados los proyectos de evaluación de la primera convocatoria del Plan, se llevaron a cabo dos tipos de acciones para facilitar a los responsable de las Universidades participantes la información técnica necesaria para el desarrollo del plan, así como a dar a conocer los objetivos y procedimientos de evaluación al conjunto de la comunidad universitaria.

1. Presentación a los Presidentes de los Comités de Evaluación de Universidad (mayo 1996).

2. Presentación a la totalidad de los miembros de los Comités de Evaluación de Universidad y de las titulaciones (junio-julio 1996). 


\section{Formación de los Comités Internos de Evaluación}

Representantes de los Comités de Evaluación de todas las titulaciones y los responsables de las unidades técnicas de evaluación de las Universidades asistieron en la ciudad de Jaca a un seminario (noviembre 1996) sobre la Guía de Evaluación, orientado especialmente al proceso de revisión interna (autoevaluación).

\section{Selección y formación de los Comités de Evaluación Externa}

El número de titulaciones que se seleccionaron en la primera convocatoria del Plan representó una importante complejidad organizativa. Dificultad incrementada por la necesidad de realizar la evaluación externa en un tiempo muy breve que requería contar con un número elevado de evaluadores externos. Los integrantes de los Comités Externos fueron seleccionados, por el Comité Técnico, conjugando la presencia de tres perfiles diferentes de miembros, con acreditada experiencia: académicos del área de la titulación; no académicos vinculados con el ámbito profesional de la titulación; y expertos en evaluación.

Los miembros de los Comités Externos, han participado en la sede del Consejo de Universidades, en dos sesiones de formación (mayo y noviembre de 1997) sobre la Guía de Evaluación, en especial sobre el proceso de evaluación externa.

\section{Coordinación de la evaluación externa}

En el mes de abril la mitad de las titulaciones no habían concluido el autoestudio y puesto que las visitas de evaluación externa deben realizarse necesariamente en períodos lectivos, la Secretaría General del Consejo de Universidades tomó la decisión de retrasar la mitad del proceso de evaluación externa hasta el mes de noviembre de 1997, de forma que al ampliar el tiempo para la realización de los autoestudios, la totalidad de la Universidades han podido concluir la primera fase de autoevaluación, en el mes de septiembre de 1997

Entre los meses de mayo y junio de 1997 conforme al calendario inicialmente previsto se realizó la evaluación externa de la mitad de las titulaciones (mayoritariamente del campo de las Ingenierías, Ciencias Experimentales), mientras que el resto se está desarrollando desde la segunda quincena del mes de noviembre de 1997.

\subsubsection{Tareas Pendientes}

El grado de cumplimiento de las actividades previstas en el Plan Nacional de Evaluación en su convocatoria de 1996, valo- rado en función de coste de cada una de las fases del proceso, se eleva a un $80,5 \%$.

La fase de revisión interna (autoevaluación), que representa el $33 \%$ del Plan, se ha realizado en su totalidad.

La fase de evaluación externa, que supone el 32\% del Plan, se ha realizado en un $50 \%$.

La creación de unidades de evaluación a través de la financiación mediante acciones especiales, que representa el 16,4\% del Plan, se ha cubierto en su totalidad.

La coordinación por la Secretaría General del Consejo de los Comités de Evaluación Externa que supone un 4,4\% del Plan se ha desarrollado completamente.

Y por último las actividades relacionadas con la gestión del plan, que suponen un $14,2 \%$ del total de las acciones previstas se ha cubierto hasta el momento en un $75 \%$.

Al finalizar el año se prevé que el grado de cumplimiento, de las actividades de la primera convocatoria se eleve hasta un 95 ó 97\%. Es importante destacar que todavía, en la fecha de concluir el plazo previsto y en el momento de redactar este informe anual, ninguna Universidad ${ }^{14}$ ha remitido al Consejo el informe final de evaluación.

\subsection{Valoración del desarrollo de la primera convocatoria}

En general, el desarrollo de la primera convocatoria del Plan es satisfactorio, si bien es susceptible de mejorar en posteriores convocatorias. La calidad del proceso de evaluación de esta convocatoria, como era de esperar, es de una gran variabilidad, que depende, entre otros, de los siguientes factores:

1. La participación, con éxito, en el Programa Experimental de Evaluación o en el Proyecto Piloto Europeo.

2. La existencia previa de unidades técnicas familiarizadas con los requisitos del proceso de evaluación.

3. La existencia de sistemas de información capaces de suministrar los datos requeridos en el proceso de evaluación.

4. La composición que las Universidades establecieron para sus comités internos y los apoyos humanos, materiales e institucionales que han recibido.

La puesta en marcha del Plan Nacional contó con el apoyo explicito de los responsables de las instituciones del sistema universitario. Los medios y las acciones de presentación constituyeron instrumentos adecuados de difusión del Plan.

El impulso de los Equipos de Gobierno de las Universidades ha sido muy positivo. En algunos casos, retrasaron el inicio 
efectivo de las actividades de evaluación hasta transferencia de los fondos asignados al Plan, demora que no puede explicarse en términos de disponibilidad económica para la realización de los proyectos, sino por la debilidad de la cultura evaluativa y la fragilidad de la infraestructura técnica de apoyo interno de las propias instituciones.

Las experiencias previas de evaluación de cada Universidad y la imagen generada por las mismas, la intensidad del apoyo institucional interno, los mecanismos de decisión sobre el proyecto presentado y las experiencias individuales de evaluación de los miembros de la comunidad universitaria son elementos que necesariamente configuran el clima del proyecto de evaluación de cada Universidad.

Los puntos más problemáticos detectados en el proceso hacen referencia a los siguientes aspectos:

1. Cuando la titulación evaluada se desarrolla en un Centro con otras titulaciones, cuando existe una gran dispersión de los grupos de investigación en los departamentos o cuando en éstos se integran áreas de conocimiento dispares o sus unidades no están integradas geográficamente, los Comités de Evaluación no han adaptado suficientemente las prescripciones de la Guía de Evaluación.

2. La falta de adecuación de las diferentes bases de datos de la institución a las demandas de un proceso de evaluación institucional ha propiciado desequilibrios importantes en cuanto a la distribución del tiempo en las diferentes fases del proceso. En ocasiones, la búsqueda de la información ha consumido las mayores energías de los diferentes agentes implicados en la evaluación.

3. La amplitud e intensidad de la fase de difusión informativa interna no ha sido en general suficiente para establecer el clima adecuado.

\subsubsection{Desarrollo del proceso de evaluación interna}

El primer resultado tangible del Plan Nacional ha sido la elaboración de la totalidad de los informes de autoevaluación previstos.

\section{Características del proceso}

A pesar de las indicaciones de la Guía de evaluación, son muy pocos los informes de autoevaluación que valoran explícitamente al proceso realizado, incluso, en algún caso extremo, no se cita la composición del Comité de Evaluación responsable del informe o la representación institucional que ostentan sus miembros.
Los casos en que se produce la descripción del proceso de autoevaluación parecen corresponder con la existencia de una mayor conciencia sobre la importancia de esta información para facilitar una interpretación ajustada del informe en el contexto de una actuación orientada a mejorar la calidad y de la situación de la unidad evaluada.

\section{Los Comités de Evaluación}

Esquemáticamente se pueden distinguir dos orientaciones básicas en la composición de los Comités de Evaluación: una subraya la representación institucional, mediante la integración de responsables de los equipos de gobierno, y otra resalta su función operativa, incorporando los responsables de la unidad evaluada y personal técnico.

Ambos objetivos son igualmente necesarios para el desarrollo eficaz del proceso de evaluación y para la viabilidad de las propuestas de mejora. El peso de cada componente en el comité refleja la solución adoptada por la Universidad. La mayor parte de los comités han combinado integrantes de ambos tipos y no se observa una regla general. En los Comités de Universidad tienen un mayor peso los responsables académicos que en los Comités de Titulación.

Cuanto mayor es el peso de la representación institucional, mayor es la responsabilidad de las estructuras de apoyo técnico al Comité y mayor el riesgo que la autoevaluación no sea asumida como propia por las unidades evaluadas. Las Universidades que han abordado la evaluación de titulaciones exclusivamente con un Comité de Universidad constituyen un ejemplo extremo de esta situación.

Superado un determinado umbral de representatividad, el componente operativo parece facilitar el desarrollo de la autoevaluación y la asunción por la unidad evaluada de responsabilidad sobre el proceso y sus resultados.

La asunción de mayor protagonismo por los responsables de la titulación evaluada se ha visto facilitada por la asignación de personal de apoyo técnico al Comité de Titulación. En este caso, la legitimidad de la evaluación ante las distintas instancias de la institución (profesorado, personal de Administración y servicios, estudiantes) se asegura estableciendo mecanismos de participación y consulta durante el proceso y observando los períodos de audiencia interna de los informes de autoevaluación.

Un ejemplo extremo de la orientación "operativa" se encuentra en alguna Universidad que explícitamente ha evitado incluir a responsables académicos en los comités de evaluación. Sin embargo, lo más frecuente es que los Comité de Evaluación de Titulación hayan estado formados por miembros de la dirección del centro y de los departamentos, por profesores, por personal 
de administración y servicios (generalmente de la secretaría del centro) y por estudiantes.

Alli donde los estudiantes no han estado presentes, los Comités de Evaluación Externa han hecho valoración negativa de esta ausencia, reclamando en ciertos casos su presencia.

En cualquier caso, se ha observado que la formación y la difusión interna del proceso no ha sido suficiente para lograr el cambio cultural imprescindible para el aprovechamiento de los esfuerzos de evaluación. Numerosos Comités de Evaluación Externa señalan que los colectivos consultados desconocían el proceso realizado y que sólo tuvieron conocimiento del Informe de Autoevaluación con motivo de la visita externa. Este desconocimiento puede atribuirse tanto a la falta de visibilidad como a la escasa importancia con que algunos colectivos valoran el proceso de evaluación.

\section{Plazos}

Pese a que una parte considerable no cubrió estrictamente los plazos inicialmente establecidos, en los informes de autoevaluación no se señalan problemas en su cumplimiento. En todo caso, las dificultades parecen haberse producido en la distribución del tiempo en el proceso interno.

Los comités parecen haber dedicado excesivo tiempo a la obtención de la información, y escaso al debate, a la integración y la interpretación-valoración de los datos y tendencias. Esta distribución del esfuerzo puede haber sido consecuencia de la escasa experiencia previa o de la tendencia general a evitar valoraciones comprometidas.

Esta experiencia podría sugerir la conveniencia de elaborar una recomendación más detallada del procedimiento de autoevaluación. Sin embargo, la diversidad de situaciones organizativas entre Universidades y entre titulaciones impiden establecer un listado secuencial de acciones aplicable en todos los casos (más allá de los grandes apartados procedimentales ya recogidos en la presentación de la guía de evaluación: información y difusión; recogida y análisis de datos; elaboración y discusión del informe; etc.).

Fuentes de información: Obtención e interpretación de datos

Los problemas apuntados en la dedicación de tiempo y esfuerzo a la obtención de los datos necesarios para el análisis institucional del desarrollo de la enseñanza y la investigación reflejan las carencias generalizadas de bases de datos fiables, actualizadas e integradas que permitan el aprovechamiento de la información para la evaluación y la toma de decisiones con respecto a los procesos académicos en el Sistema Universitario.
En general, esta dificultad ha sido superada parcialmente recogiendo durante el proceso de autoevaluación la información respecto a las prácticas o a los resultados individuales de los profesores en la enseñanza y en la investigación. Más difícil ha sido, en los plazos de este proceso, la obtención de la información que requiere un procesamiento por el sistema de gestión institucional (como los datos referidos a las tasas de éxito en la enseñanza y en la investigación).

Pese a estas dificultades, en general, los informes se han ajustado a la estructura de la Guía de evaluación y reflejan adecuadamente la información disponible (aunque algunos Comités de Evaluación Externa han encontrado casos que soslayan puntos, aspectos o dimensiones expresamente señalados en la Guía).

Las carencias de información no han impedido la descripción de los procesos de enseñanza e investigación y gestión. Sin embargo, esta información no parece haber sido aprovechada suficientemente por los Comités de Evaluación, pues son escasos los informes que han pasado de la mera descripción a la interpretación crítica de los datos y son aún más escasos los análisis de tendencias.

A pesar de ello, los Comités de Evaluación Externa han considerado, en base a la información de las audiencias y de la observación directa, que la mayoría de los autoestudios reflejan adecuadamente los puntos fuertes y débiles de la titulación (en general, coherentes con los datos recogidos en el resto del informe). En otros casos, se ha apreciado que este análisis refleja exclusivamente la perspectiva del profesorado, es poco claro en cuanto a los resultados, no está avalado por la información pertinente ni explícita planes de mejora.

\section{Relación entre proceso y resultados}

Desde el punto de vista de los resultados, la eficacia de las soluciones parece similar en las distintas instituciones, pues los resultados de la autoevaluación (en cuanto a la obtención y aprovechamiento de la información, en cuanto a la implicación de la titulación y en cuanto a la realización de análisis críticos e integradores) no parecen depender de la composición del Comité.

En ese sentido, los procesos de autoevaluación y sus resultados han sido, en líneas generales, menos problemáticos en las titulaciones que implicaban el análisis de un solo departamento que en aquellas que implicaban varios departamentos o la totalidad de un centro aunque pueda haber habido dinámicas de trabajo bastante diferentes entre los distintos departamentos o centros.

En los casos de titulaciones que implican más de un departamento es relativamente frecuente la falta de integración entre los análisis de las distintas unidades. Esto es más evidente en la 
evaluación de la investigación, donde suele no realizarse la integración entre departamentos.

Los procesos en las unidades departamentales han tenido mayor capacidad de concitar el compromiso colectivo con el proceso de evaluación y disposición a aprovecharlo para la mejora.

Según los diferentes estilos de dirección y de organización interna del Comité de Evaluación, aquellos que contaban con equipos reducidos de responsables o con una división participativa del trabajo han sido más eficaces en la resolución de los problemas planteados por el proceso.

Aunque el tamaño y la complejidad relativa de la unidad son factores influyentes, la calidad del proceso no puede atribuirse totalmente a ellos y los resultados no fueron sustancialmente diferentes desde el punto de vista del proceso, pese a que se dieron diferencias notables entre titulaciones en cuanto:

1. Contexto institucional (tipo de Universidad, tamaño, antigüedad).

2. Tipo de titulación (ciclo corto/largo, red de conocimiento).

3. Composición del profesorado (categorías, dedicación).

4. Organización del proceso, especialmente en cuanto a la participación en la elaboración del auto-informe.

5. Disposición favorable al proceso y experiencia profesional relevante.

En cambio, la capacidad para concitar el compromiso y la implicación colectiva, la eficiencia organizativa y la cultura institucional parecen ser factores importantes para el éxito del proceso.

En los casos en que el Comité de Evaluación de la Titulación decidió una división técnica del trabajo según áreas de evaluación (enseñanza, investigación, gestión), los Comités de Evaluación Externa han encontrado con mayor frecuencia problemas en el proceso de elaboración o en la integración final del autoestudio.

Ventajas y riesgos del procedimiento de autoevaluación

El procedimiento de autoevaluación destaca la responsabilidad de la propia unidad sobre el proceso y los resultados de la evaluación. Este diseño supone (para bien o para mal) que los procesos están condicionados por la situación y la dinámica de funcionamiento interno de las instituciones. Esto se refleja tanto en la capacidad del Comité de Evaluación para concitar el interés, la colaboración y la participación de los diferentes sectores de comunidad universitaria, como en el proceso de elaboración (recogida de datos, síntesis/integración de aspectos, valoracio- nes y críticas, propuestas) y en el grado de consenso sobre el informe.

Como consecuencia, en los casos problemáticos se plantea un dilema respecto al valor de los productos de la autoevaluación:

Pueden ser un buen reflejo de la realidad existente, lo que representa una información sobre la situación de la organización valiosa en sí misma desde el punto de vista del diagnóstico institucional.

Pero pueden ser poco valiosos desde el punto de vista de su calidad técnica, en aspectos como: limitaciones en la fiabilidad y validez de los datos informados, escaso aprovechamiento de los datos disponibles, análisis poco equilibrado entre autocrítica y autocomplacencia, falta de integración y síntesis: no identificación de los aspectos fuertes y débiles y ausencia de propuestas viables de mejora, falta de precisión en la responsabilidad de actuación respecto a la mejora de los aspectos débiles y respecto a las propuestas de mejoras (o su atribución exclusiva a factores externos), dudas en la legitimidad del informe, escasa utilidad del informe para debate y mejora internos o para la comparación externa.

Estos casos pueden llegar, incluso, a ser contraproducentes a corto y largo plazo. A corto plazo, porque pueden generar tensiones internas respecto a la responsabilidad de la decisión y. del desarrollo del proceso de autoevaluación, contestación y falta de colaboración en el proceso y, finalmente, escepticismo respecto a los objetivos, el proceso y sus resultados. El efecto inmediato puede ser el desgaste de los equipos intervinientes, tanto los responsables directos del proceso de autoevaluación (especialmente de la elaboración del informe) como de los responsables académicos de la unidad y, finalmente, de la unidad técnica. El efecto perverso a largo plazo es el desprestigio general del proceso y de los agentes de evaluación.

Estos posibles efectos perversos de la autoevaluación problemática pueden neutralizarse al contrastar el proceso interno mediante la evaluación externa y asegurando la visibilidad de las consecuencias de la evaluación para la institución y la titulación participantes.

\subsubsection{Desarrollo del proceso de evaluación externa}

Dos salvedades han de apuntarse a fin de valorar adecuadamente el contenido de este apartado:

1. Al no haber finalizado la elaboración de los informes finales se desconoce la valoración que los destinatarios de la evaluación realizarán de esta fase del proceso general. 
2. Las fuentes de información utilizadas se centran exclusivamente en el contenido reflejado en los Informes emitidos por los Comités de Expertos Externos.

La valoración del proceso de evaluación por los Comités de Evaluación Externa

Salvo algún caso aislado, todos los COMITÉS DE EVALUACIÓN EXTERNA han abordado este punto en su informe. Del análisis de este apartado cabe destacar una serie de valoraciones que conforma una imagen positiva del proceso general de evaluación.

1. Hay unanimidad acerca de la pertinencia y útilidad de la fase de evaluación externa.

2. Esta fase de evaluación se ha llevado a término con un cumplimiento escrupuloso del proceso de evaluación diseñado, ajustándose a las indicaciones de la Guía de Evaluación Externa.

3. Los diferentes Comités de Evaluación Externa han detectado un clima generalmente satisfactorio o muy satisfactorio durante la visita. Algunas de las suspicacias o reticencias iniciales han sido como consecuencia de fallos en los procesos internos de información-comunicación-implicación de las unidades evaluadas.

4. No se señalan especiales problemas de inadecuación de su informe. La ausencia de información sobre la fase de reacción de la titulación al informe del Comité de Evaluación Externa puede interpretarse como un indicador de la ausencia de conflictos en cuanto a la confrontación Evaluación interna-Evaluación externa. Se ha cumplido el principio de la complementariedad defendido en el modelo adoptado a falta, claro está, de la valoración de los destinatarios de la evaluación.

5. Se otorga una valoración positiva de la colaboración y ayuda prestada al Comité de Evaluación Externa por la Unidades Técnicas de Evaluación de las Universidades, allí donde estaban constituidas con una mínima infraestructura y organización.

6. Se da también una positiva valoración de la documentación técnica de apoyo a su tarea, con especial referencia a la Guía de Evaluación Externa.

7. Valoración positiva del número y tipología de las audiencias incluidas en el proceso de evaluación externa. Las objeciones-sugerencias se refieren a los siguientes aspectos: Audiencias diferentes del equipo directivo y la dirección de los departamentos; Audiencia específica para alumnos de tercer ciclo; Asegurar una presencia significativa de egresados; Mayor disponibilidad horaria para la visita a las instalaciones.

8. Valoración positiva de la participación de las diferentes audiencias, dándose casos aisiados en los que los participantes en la audiencia no conocían el contenido del Autoestudio elaborado.

Los aspectos más problemáticos a juicio de los Comités de Evaluación Externa hacen referencia a tres puntos:

1. No disponer con el tiempo previsto (1 mes) del Autoestudio es valorado como factor negativo en el trabajo del Comité de Evaluación Externa. En los casos en los que sí se ha dado dicho plazo, la valoración de esta fase (análisis del Autoestudio) es muy positiva.

2. Elevado consenso en cuanto a la falta de tiempo para una visita con cierto sosiego y reflexión. Cuando el traJajo del Comité de Evaluación Externa demuestra profundidad, interés y compromiso con la institución, aparece la clara sugerencia de incrementar en un día el período de la visita externa.

3. Algunos Comités de Evaluación Extema han valorado como deficiencia la ausencia de un experto externo del campo profesional relacionado con la titulación evaluada. Salvo en una Universidad, que por ampliar a cuatro el número de expertos externos ha incluido uno o dos expertos profesionales, raras han sido las situaciones en las que se ha contado con este tipo de experto. Asimismo, y en algún caso, se ha sugerido la presencia de un experto académico internacional.

\section{Valoración de la evaluación externa}

En los apartados siguientes se analiza la calidad del trabajo realizado por los Comités de Evaluación Externa en relación a dos dimensiones: la estructura del contenido de evaluación y la naturaleza de la evaluación realizada. En la primera se examina el cumplimiento de las indicaciones çontenidas en la Guía de Evaluación. Y en la segunda se examina la naturaleza y tipología de los juicios de valor emitidos.

\section{La estructura del contenido del informe de evaluación externa}

En términos generales los Comités de Evaluación Externa han abordado de manera sistemática los diferentes subapartados de cada una de las tres dimensiones evaluadas (enseñanza-investigación-gestión), si bien es cierto que dicha sistematización es mucho más evidente en la enseñanza que en la investigación y en bastante menor grado en la gestión. 
En un solo caso se argumenta que no es necesario realizar ninguna otra evaluación de la investigación que vaya más allá de la realizada en el marco de los tramos de investigación.

La calidad del trabajo realizado por los Comités de Evaluación Externa puede ejemplificarse resaltando dos casos extremos:

1. Ante un Autoestudio escasamente estructurado y argumentado, el Comité de Evaluación Externa realizó un informe de evaluación excelente, reelaborando con datos, argumentos y juicios de valor el débil Autoestudio realizado.

2. Ante un Autoestudio formalmente correcto, aunque sin grandes dosis de profundidad, el Comité de Evaluación Externa realizó un informe superficial, dedicando sólo algunos párrafos a la valoración de la enseñanza y la investigación. Podría considerarse también paradigmático del trabajo mal realizado.

En términos generales los Comité de Evaluación Externa incluyen en sus informes valoraciones y recomendaciones de mejora de la calidad.

La valoración realizada de los puntos fuertes y débiles integrando los puestos de manifiesto en el Autoestudio (con matizaciones y precisiones del propio Comité Externo para cada punto propuesto) con los identificados por el Comité de Expertos Externos, son una muestra de la alta calidad del trabajo de gran parte de los Comités Externos.

La naturaleza de la evaluación realizada

Los Comités Externos han intentado establecer juicios de valor - a veces fragmentarios- sobre la unidad evaluada. Tan sólo alguno de los Informes de los Comités Externos simplemente describen (en forma de síntesis) el contenido del Autoestudio, sin establecer ningún tipo de contraste.

En general, los Comités de Evaluación Externa han sido más propicios a aportar datos en sus juicios sobre la investigación que sobre la enseñanza o la gestión. Podría deducirse que los Comités Externos, al carecer de estándares de calidad en los ámbitos de la enseñanza y la gestión, tienen dificultades técnicas o falta de consenso en los criterios, para identificar los datos relevantes en relación a la calidad de una titulación.

Con demasiada frecuencia la evaluación externa se ha centrado en aspectos de carácter organizativo, procedimental o de cantidad, en detrimento de aspectos más profundos. En la enseñanza, se subraya el número de profesores, pero no su formación, o se explicita la buena organización administrativa de los exámenes, pero no se menciona la pertinencia de sus formas y contenido en relación a los objetivos de formación.
Finalmente, ha de destacarse que algunos Comités Externos han realizado una seria reflexión sobre la calidad intrínseca del plan de estudios (desde la perspectiva científica y de formación de profesionales) que ha ido más allá de la simple descripción de la estructura académica y administrativa del plan.

En un modelo de evaluación orientado a la mejora una de las funciones de los Comités de Evaluación Externa es hacer de consultores de la organización evaluada en relación a las acciones a emprender para elevar el nivel de calidad de la misma. En consecuencia, han de ajustarse a hechos y posibilidades las propuestas explicitadas. En este sentido, parte significativa de las recomendaciones de los Comités Externos presentan cierta dificultad.

En general, la mayor parte de las recomendaciones van dirigidas al sistema (Universidad-Administración) y son del tipo de las siguientes:

1. Mayor y mejor control en el acceso de alumnos (menos plazas + selectividad).

2. Más y mejores recursos (profesores, laboratorios, bibliotecas, ...).

3. Menor carga docente ...

Sólo en ciertos informes, los Comités Externos abordan propuestas de mejora realizables por la propia titulación y son del tipo de las siguientes:

1. Mayor atención-información a los alumnos.

2. Adecuación de los programas.

3. Adecuación de la optatividad, etc...

Las atribuciones externas de las situaciones de déficit, así como la enfatización en la aportación de recursos externos como factor fundamental para el incremento de la calidad es, en buena parte, consecuencia de un marco de referencia que corresponde con una cultura con escaso predominio de un modelo autónomo de gestión.

\section{Resultados de la primera convocatoria del Plan Nacional de Evaluación}

En este capítulo se recogen las principales observaciones formuladas como puntos fuertes y débiles en los Informes realizados por las Universidades que evaluaron algunas de sus Titulaciones en la primera convocatoria (OM de 21 de febrero de 1996) del Plan Nacional de Evaluaición de la Cali- 
dad de las Universidades (R.D. de 1 de diciembre de 1995). Se señalan conclusiones generales en relación con la enseñanza, la investigación y la organización universitaria. Dadas las características de la primera convocatoria, en la que las Universidades, sin orientación previa sobre campos específicos, definieron las titulaciones que evaluarian y dado que de forma general el Consejo de Universidades propuso subvencionar la totalidad de los proyectos, en ningún caso, aunque participan todas las Universidades, los resultados que se presentan pueden considerarse una muestra estadísticamente representativa del sistema universitario.

La Universidad española conforma un sistema complejo, en expansión desde la mitad de los años sesenta y sometido a considerables tensiones producto de la diversidad y heterogeneidad de las demandas que recibe desde el sistema social, económico y político.

El tamaño del sistema puede resumirse con los siguientes parámetros:

1. En todas las Comunidades Autónomas hay, al menos, una Universidad.

2. En casi todos los municipios de más de 50.000 habitantes hay algún centro universitario.

3. El número de alumnos supera el millón y medio. La tasa de escolarización casi se ha multiplicado por tres en los últimos 25 años y ha pasado de ser una de las más pequeñas (en 8. lugar de Europa) a situarse en la banda alta de la Unión Europea (3.ำ lugar) y de la OCDE

4. El número de titulados universitarios supera ampliamente los tres millones. La tasa de titulación superior, aunque sigue siendo de las más bajas de Europa y de la OCDE, se ha multiplicado casi por dos en los últimos 10 años.

5. El gasto en enseñanza superior que representa el $1 \%$ del Producto Interior Bruto se ha multiplicado por cuatro en los últimos 20 años.

Transformaciones cuantitativas, propiciadas por un cambio sustancial, producto del programa constitucional, que al garantizar el derecho a la autonomía de las nacionalidades y regiones y reconocer la de la Universidad, en el marco de un Estado social y democrático de Derecho, propició una profunda alteración de los sistemas universitario y científico, que se expresó en la Ley Orgánica 11/1983, de 25 de agosto, de Reforma Universitaria y en la Ley $13 / 1986$, de 14 de abril, de Fomento y Coordinación General de la Investigación Científica y Técnica.

La situación de la Universidad española puede sintetizarse resaltando sus puntos fuertes y subrayando sus debilidades.
Entre los primeros el incremento de la calidad y de la cantidad de la producción científica o su capacidad para atender una demanda de enseñanza creciente cada vez más diversificada.

Y entre los segundos en muichos casoss la indefinición de objetivos o la continuidad de estrategias educativas tradicionales.

Aspectos a los que se suman dificultades estructurales, producto de los cambios organizativos y ventajas derivadas de la diversificación y flexibilización curricular.

\subsection{La enseñanza}

En el ámbito docente la multiplicación y diversificación de la oferta de titulaciones universitarias junto a la reforma de los planes de estudio constituyen los elementos principales que determinan la situación de la enseñanza universitaria.

En lá Úniversidad española está muy extendida la idea de que es necesario incorporar elementos de planificación y racionalización que articulen el proceso docente. Al tiempo que se reclama una revisión de los planes de estudio que permita reconsiderar las funciones de la institución universitaria.

\subsubsection{Metas y objetivos de las titulaciones}

Indefinición de objetivos

Generalmente las titulaciones no cuentan con una formulación explícita de las metas y objetivos que justifiquen y orienten su programa docente. En la mayoría de los informes de evaluación los objetivos de la titulación se expresan de forma genérica, limitándose a la transcripción de las respectivas directrices generales.

Habitualmente las titulaciones tampoco cuentan con mecanismos de comprobación de la consecución o de la viabilidad de los objetivos propuestos, que permitieran, en su caso, reorientar las estrategias de actuación y los procesos de enseñanza en la titulación.

En consecuencia, dado que gran parte de las enseñanzas se desarrollan sin señalar explícitamente las metas en relación a las cuales se pueda valorar su calidad se opta habitualmente por utilizar indicadores indirectos de calidad (nota de acceso a los estudios, nivel de exigencia, tasa de éxito, tasa de empleo, etc...) que generalmente se interpretan de forma excesivamente simplificada y parcial.

Imprecisión del perfil profesional y académico

Existe una gran disparidad e imprecisión en relación con los perfiles profesionales y académicos que se señalan como orien- 
tación formativa. En los casos en los que se establecen perfiles definidos no se justifican adecuadamente mediante estudios prospectivos sobre las necesidades sociales y del mercado laboral, ni tampoco sobre la lógica académica de cada titulación.

Por otra parte, en muchas ocasiones no existen procedimientos para analizar las condiciones de inserción profesional de los graduados que permitieran conocer la evolución de la demanda y las necesidades formativas requeridas desde el plano profesional.

\section{Indiferenciación de los programas docentes}

Cuando existen, ni en la formulación de metas y objetivos ni en la definición de los perfiles profesionales o académicos existe una clara diferenciación entre las titulaciones de ciclo corto (diplomaturas) y de ciclo largo (licenciaturas) que pertenecen a un mismo campo científico. La diferenciación entre ciclos se establece exclusivamente en términos de carga teórica sin tener en cuenta la orientación profesional o académica de los estudios.

\subsubsection{Planes de estudios}

Disfuncionalidad de los planes de estudio

La gran mayoría de los informes de evaluación ponen de relieve la existencia de disfuncionalidades en la ordenación y estructuración de los Planes de Estudios.

Existe una gran disparidad de criterios en relación con la estructura del programa formativo de cada titulación, que se pone de manifiesto por el desajuste entre la dimensión teórica y práctica de los planes, por la disparidad en los índices de optatividad, por la configuración de las materias de libre configuración, o por la falta de previsiones sobre los niveles formativos previos, etc...

Buena parte de los informes analizados subrayan desajustes entre los perfiles de las titulaciones y la propuesta formativa. Se señala entre otros aspectos la presencia de itinerarios curriculares centrados principalmente sobre intereses academicistas.

Disfuncionalidades que se ponen de relieve en la configuración de la estructura lectiva de los planes de estudios: la multiplicación del número de asignaturas, el excesivo número de horas de clase y la presencia de asignaturas con reducido número de horas de clase, son algunos de los ejemplos significativos.

Mejora de los procesos de orientación

Respecto a la información académica que reciben los estudiantes, se observa que cada vez más los centros elaboran Guías di- dácticas con el fin de orientar al alumnado sobre los objetivos y contenidos relativos a las diversas asignaturas que configuran una titulación.

Escasa coordinación y adaptación de los programas a los nuevos planes

En los programas de las asignaturas se detectan deficiencias en los siguientes aspectos:

1. Falta de coordinación intra e interdepartamental en relación con los objetivos, contenidos, actividades y criterios de evaluación específicos de las asignaturas del plan de estudios.

2. Escaso seguimiento de los programas docentes para evaluar tanto la adaptación de sus contenidos al nivel formativo previo de los alumnos como el ajuste de su extensión al período temporal asignado para cada asignatura.

3. Ausencia de mecanismos de revisión que permitan valorar la adecuación y actualización de los contenidos establecidos en cada una de las asignaturas con el fin de evitar tanto lagunas como exigencias no pertinentes en relación a los objetivos propios de una titulación.

Mejora de la organización de la enseñanza

Se constata que durante los últimos años se ha realizado un esfuerzo significativo para planificar y organizar adecuadamente los procesos de enseñanza. En general, cabe señalar que éste ha sido un objetivo que se ha cubierto de forma satisfactoria aunque todavía pueden, entre otras, señalarse las siguientes deficiencias:

1. En algún caso se mantienen índices de alumnos por grupo muy elevados.

2. No siempre existen criterios y orientaciones en relación con la organización de las enseñanzas por cuatrimestres que ayuden al profesor a adaptar y revisar sus programaciones docentes.

\subsubsection{Desarrollo de la enseñanza}

Enseñanza tradicional

El método docente utilizado en las aulas sigue siendo mayoritariamente la clase "magistraln basada en la explicación del profesor y como consecuencia se constata: 
1. Una baja participación del alumno en las clases que se limita a mantener una actitud meramente receptiva.

2. El escaso fomento del trabajo personal del alumno mediante estrategias apropiadas (consuita de textos, trabajo en equipo, etc...).

3. La falta de diferenciación entre créditos teóricos y créditos prácticos dentro de cada asignatura que lleva al profesorado a utilizar el mismo tipo de metodología en ambos casos.

4. La continuidad de una cultura sobre la ineficacia de la docencia universitaria al no ser necesaria la asistencia a clases para superar la mayor parte de las asignaturas.

Percepción positiva de calidad de la enseñanza

Sin perjuicio de las debilidades señaladas en relación con el método docente, desde la perspectiva de los alumnos, la calidad de las enseñanzas recibidas es valorada en muchas ocasiones de forma satisfactoria y se subrayan los siguientes aspectos:

1. El dominio y competencia que los alumnos atribuyen a la mayoría de los profesores sobre la materia que imparten.

2. El elevado nivel de cumplimiento de los programas propuestos.

Ineficacia del sistema de tutorías

Se constata el bajo nivel de funcionamiento de las tutorías cuya actividad se limita exclusivamente a la revisión de exámenes.

Inadecuación de los sistemas de evaluación de los aprendizajes

En casi todos los casos, también se constata la ausencia de mecanismos de evaluación de los aprendizajes que tengan en cuentan criterios objetivos referidos al rendimiento global.

Los procesos de evaluación de los aprendizajes son los peor valorados por el alumnado universitario. Entre los argumentos que utilizan para justificar su insatisfacción pueden destacarse los siguientes:

1. La falta de coherencia y publicidad de los criterios de evaluación que se van a utilizar en las diversas asignaturas. La ausencia de unos criterios generales determina que cada profesor establezca su propio baremo y que las diferencias entre las distintas materias sean muy acusadas.

2. Se tiende a centralizar los procesos de control del aprendizaje sobre un único examen sin tener en cuenta otros datos (asistencia, trabajos personales, prácticas, etc...).
3. El desajuste entre el contenido que ha sido objeto de explicación de las clases y el nivel exigido en los protocolos de examen. Las diferencias se manifiestan especialmente en determinadas titulaciones y materias donde los conocimientos suelen ser evaluados mediante procedimientos de aplicación de contenidos expuestos de forma teórica.

Mejora de los servicios universitarios

Los servicios universitarios de orientación y asistencia al alumnado han mejorado considerablemente aunque todavía se observan las deficiencias en la siguientes áreas:

1. Orientación e información académica y profesional tanto en el momento de matricularse por primera vez en la Universidad como en la fase final para su incorporación al mundo laboral.

2. Información sobre los derechos y deberes del alumnado así como de los cauces a través de los cuales pueden canalizar sus iniciativas, reclamaciones y participación en los procesos de gestión académica.

3. Organización de actividades curriculares y extracurriculares a través de las cuales el alumnado pueda participar y canalizar sus intereses culturales y formativos.

\subsubsection{Resultados académicos}

Escaso rendimiento .

La nota más destacada que se desprende de los informes revisados es el bajo nivel de rendimiento del sistema universitario tal como se pone de relieve en los bajos porcentajes de éxito, en las elevadas tasas medias de retraso (en torno a dos cursos), o en el alto nivel de abandono, etc...

Rendimiento cuya variabilidad es muy alta en función de la titulación, dẹ ciclo, de la asignatura, o incluso del profesor. Las tasas de fracaso más elevadas se originan en los primeros cursos de las titulaciones donde siempre existen algunas materias que actúan como filtro selectivo y en aquellas donde la actividad docente es compartida por varios profesores. En los segundos ciclos las tasas de éxito son más elevadas, especialmente en las materias optativas.

Las diferencias en las tasas de presentados y aprobados entre las materias de un mismo curso y en una misma asignatura impartida por distintos profesores son en algunos casos tan acusadas que cuestionarían la credibilidad del sistema de evaluación empleado. 
Ineficacia del método de revisión de exámenes

En la mayoría de las instituciones evaluadas existe una normativa que regula la revisión de los exámenes así como las reclamaciones que procedan. Sin embargo, los alumnos manifiestan la inoperancia de estas normas ya que en relación con las calificaciones el profesorado parece contar con un margen de discrecionalidad muy alto.

Variabilidad de la valoración de la calidad de los resultados

Respecto a la calidad de los resultados la valoración es muy desigual según las titulaciones. Mientras que en algunas sus egresados son reconocidos por su buen nivel de conocimientos - titulaciones científicas y técnicas superiores- en otras la calidad de los aprendizajes no constituye un criterio prioritario en la evaluación de los resultados.

\subsubsection{Alumnos}

Insatisfacción del sistema de acceso

La primera conclusión que se deduce de los informes revisados es el rechazo que formulan las instituciones ante el incremento de la matrícula de nuevo ingreso que experimentan determinadas titulaciones. Las Universidades vinculan las oportunidades de mejorar la calidad de la enseñanza a una reducción del número de alumnos de nuevo ingreso.

Para valorar los indicadores de rendimiento se subraya la necesidad de tener en cuenta las diferencias que existen en el alumnado de una misma titulación según el sistema de selección: Para el primer ciclo: Pruebas de Acceso, Formación Profesional, Pruebas para mayores de 25 años, etc...; y para el segundo ciclo: Primer ciclo de la misma titulación o Pasarelas.

Muchos informes insisten en que la diversidad en la tipología de los alumnos según ámbitos de procedencia constituye uno de los criterios para valorar los resultados, pese a lo cual en las titulaciones no se han establecido procedimientos de revisión y análisis que permitan observar la relación entre las características de los alumnos (admitidos en primera opción, sistema de acceso, dedicación parcial al estudio, becario, etc...) y su rendimiento académico (tasas de presentados, éxito, retraso y abandono). Y tampoco estrategias didácticas diferenciadas para las necesidades de los distintos colectivos.
Imprevisión en relación con el nivel de exigencia

En muchas ocasiones no se considera ni se prevén alternativas en relación con el tiempo que el alumno debe dedicar al estudio para obtener un rendimiento satisfactorio de acuerdo con la planificación prevista.

En el diseño de los planes de estudio no se ha tenido en cuenta el número de horas total al día o a la semana, que debe emplear un alumno para cumplir con el conjunto del plan en los tiempos previstos. Incluso, en algún caso, si se suman las expectativas de los profesores sobre el tiempo de trabajo personal del alumno (a veces 3 horas por cada hora de clase), con el horario docente el resultado es imposible.

\subsubsection{Profesorado}

Valoración positiva de la calidad del profesorado

Todos los informes tienden a resaltar el alto nivel de capacitación, competencia y dedicación del profesorado, se coincide en resaltar que este aspecto constituye uno de los principales puntos fuertes del sistema universitario.

\section{Valoración negativa de las políticas de personal}

Sin perjuicio de la valoración positiva sobre el profesorado, gran parte de los informes de evaluación resaltan la precariedad de las políticas de recursos humanos. Las notas más destacadas que justifican esta conclusión son las siguientes:

1. Ausencia de políticas para la captación de doctores y buenos profesores con el fin de incorporar a la actividad docente personas con prestigio académico y que a su vez tengan una fuerte vinculación con el mundo profesional.

2. Desajustes entre la plantilla teórica y real lo que implica excesivo número de profesores no cualificados, especialmente en aquellas titulaciones de reciente implantación.

3. Escasa racionalización de los procesos de adscripción de la docencia lo que origina claras descompensaciones entre los profesores más jóvenes y menos cualificados, que tienen mayor sobrecarga docente tanto a nivel de asignaturas, créditos y alumnos, y los más experimentados.

4. Falta de criterios claros y explícitos en relación con los sistemas de promoción profesional que traslada las expectativas de carrera docente a decisiones circunstanciales. 


\section{Escasa formación y cualificación pedagógica}

También pese a la valoración positiva del profesorado, otra de las conciusiones más destacadas en casi todos los informes es la poca atención que se presta a la formación y cualificación pedagógica del profesorado. Esta carencia es sentida por gran parte del profesorado que considera conveniente recibir una formación apropiada al respecto, especialmente cuando se comienza a ejercer la función docente.

Inadecuación de los procedimientos de evaluación del profesorado

A menudo los profesores se manifiestan de forma crítica respecto al sistema de evaluación de la actividad docente implantado en la mayoría de las instituciones (las encuestas de opinión al alumnado) ya que, desde su punto de vista, con las pautas actuales, ofrecen una visión del trabajo docente muy reduccionista y los departamentos no establecen ninguna fórmula operativa que les permita incluir la información de las encuestas en las decisiones destinadas a mejorar la calidad de la enseñanza.

\section{Ineficiencia de los Departamentos}

En muchos informes se pone de relieve la inoperancia de los departamentos universitarios como órganos de formación y coordinación didáctica, dado que mayoritariamente se limitan únicamente a tareas burocráticas.

\subsubsection{Instalaciones}

Mejora de las instalaciones

Con carácter general se constata el gran esfuerzo realizado por las Universidades para dotar a los centros de instalaciones que permitan desarrollar la enseñanza en condiciones adecuadas.

Salvo en contadas situaciones se subraya que las instalaciones han mejorado sensiblemente durante los últimos años. Sin perjuicio de lo cual se señalan las siguientes deficiencias:

1. Insuficiencia de recursos para las actividades prácticas, especialmente cuando se comparan con las dotaciones y medios con que se cuenta para investigación.

2. Escasez de espacios para los alumnos dentro de las instalaciones académicas. De manera especial las quejas se centran sobre las dotaciones y funcionamiento de las bibliotecas.
3. Poca utilización de los medios y recursos tecnológicos de que dispone la institución en el desarrollo de la actividad docente en las clases.

Inadecuación del uso de los recursos disponibles

Como observacion global de este apartado se puede concluir que, en las titulaciones consolidadas, generalmente los problemas se plantean más a causa de la escasa racionalización en el uso de los recursos que a la carencia de los mismos.

\subsubsection{Relaciones externas}

Mejora de las relaciones de cooperación interuniversitarias

Se valora positivamente que, durante los últimos años, todas las Universidades han realizado un esfuerzo notable para establecer relaciones de cooperación con diversas instituciones a fin posibilitar el intercambio de alumnos y profesores. No obstante, esta conclusión debe ser matizada ya que presenta ciertas peculiaridades que procede resaltar:

1. Generalmente, estas relaciones se establecen a nivel internacional bajo el auspicio de programas europeos y apenas existen dentro del contexto nacional a pesar de su importancia académica.

2. Existe un claro desajuste entre las relaciones que establecen las titulaciones —orientadas específicamente al intercambio de alumnos- y las que mantienen personalmente los profesores más vinculados a la investigación.

\section{Debilidad de las relaciones Universidad-Empresa}

Una de las carencias que han sido detectadas en todas las evaluaciones realizadas es la escasa vinculación del mundo académico con el mundo profesional. Algunos de los datos puestos de relieve son los siguientes:

1. Escasez de acuerdos y convenios establecidos entre las instituciones y las empresas que permitan un conocimiento mutuo y la coordinación de esfuerzos con el fin de que la formación de los egresados se ajuste más a los requerimientos del mercado de trabajo.

2. En aquellas titulaciones que requieren proyectos fin de carrera y prácticas en empresa se acusa la falta de diseños coherentes de estas actividades académicas que respondan a las necesidades concretas con el fin de que puedan realizarse en escenarios reales. 


\subsection{La investigación}

Entre los investigadores españoles está muy extendida la conciencia de que en los últimos años se ha producido un notable aumento en la cantidad y la calidad de la investigación que se realiza en España. Esta sensación es especialmente clara entre investigadores de ciencias experimentales y tecnología, y menos definida en las áreas humanísticas y sociales. Por otra parte, los indicadores objetivos de actividad científica y de resultados avalan esta impresión subjetiva. A título de ilustración, sabemos que la presencia de investigadores españoles en las bases de datos internacionales de producción científica ha crecido espectacularmente, tanto en cantidad como en calidad. Paralelamente se constata una mayor integración de la ciencia española con la europea, a través de proyectos de colaboración internacional. Estas características se observan en general en la producción científica española, no sólo en la universitaria, pero debe tenerse en cuenta que la presencia de los investigadores universitarios en el total de la producción científica española es superior al 70\%.

Está también muy extendida (y también desigualmente distribuida entre los diferentes campos científicos) la aceptación de la evaluación de la investigación, como una práctica normal en la actividad científica. Esto no quiere decir, naturalmente, que exista unanimidad respecto al método en los instrumentos de evaluación, y menos aún respecto a los resultados y a las consecuencias que la evaluación pueda tener para los investigadores y la instituciones evaluadas.

En relación con este punto, es importante destacar un problema que aparece en numerosos informes: los profesores universitarios están acostumbrados a que se evalúe su actividad investigadora, a través de la Agencia Nacional de Evaluación y Prospectiva (evaluación de proyectos) o de la Comisión Nacional de Evaluación de la Actividad Investigadora (evaluación de tramos de investigación), pero les resulta difícil asumir la perspectiva de la evaluación institucional. En este caso no se trata de evaluar la actividad de los investigadores considerados individualmente sino de las instituciones (los departamentos). Y lo difícil para muchos universitarios es entender siquiera que exista una dimensión institucional de la investigación universitaria que no sea la simple suma de las aportaciones de cada individuo.

Esta dificultad ha sido agravada a veces por las ambigüedades existentes en la propia guía de evaluación. En teoría, la unidad de evaluación de la investigación debe ser el departamento, sin embargo la unidad central del proceso de evaluación son las titulaciones y no parece que se hayan aplicado criterios homogéneos para la determinación de los departamentos a evaluar (idealmente se deberían haber escogido los que tuvieran una presencia mayor en las titulaciones evaluadas). De hecho, las opciones presentes van desde los casos en que los comités han evaluado solamente la investigación realizada por los profesores de cualquier departamento que daban clase en una titulación, hasta la constitución de comités específicos por departamento, desvinculados del comité de titulación.

A pesar de estas dificultades, debe señalarse, sin embargo, que en la mayoría de los casos, la participación de los investigadores en los comités ha generado un cierto aprendizaje del método de evaluación institucional que les ha permitido llegar a conclusiones interesantes y a valorar muy positivamente su propia participación en el ejercicio.

\subsubsection{Objetivos}

\section{Indefinición de objetivos}

Con carácter general destaca la práctica inexistencia de objetivos definidos y planes de desarrollo y de calidad de la investigación en el ámbito de los departamentos analizados.

$\mathrm{Ni}$ en el nivel del departamento ni en el de la Universidad se definen en el ámbito de la investigación. La situación más común es que se considere que los objetivos de investigación son un asunto "privado" a gestionar entre el investigador o equipo de investigación y las agencias que convocan programas de financiación de la investigación. Generalmente, el departamento no se percibe como un lugar adecuado para definir objetivos institucionales relativos a la investigación, sino más bien como una entidad administrativa en la que se deben tramitar determinados asuntos académicos (distribución de asignaturas, peticiones de plazas, aprobación de propuestas de tesis, etc.).

\subsubsection{Recursos}

Incremento de los recursos

De forma general, se considera como un punto fuerte el incremento que se ha dado en los últimos años en profesorado y recursos para la investigación.

Sin embargo, apenas existe financiación interna, de la propia Universidad, para la investigación, y cuando existe, se la considera poco relevante en relación con las fuentes externas de carácter nacional e internacional.

\section{Escasez de medios de apoyo}

Se considera un obstáculo para la investigación la carencia de personal de apoyo estable, tanto de carácter técnico como administrativo. 
Otra queja bastante generalizada, relacionada con el punto anterior, se refiere al exceso de tareas burocráticas y de gestión que recaen sobre los investigadores, por falta de técnicos adecuadamente preparados.

Aunque se considera que ha mejorado mucho el nivel de dotación de infraestructuras para la investigación, se señalan con frecuencia insuficiencias de infraestructura tanto instrumental como bibliográfica, etc.

Es especialmente significativa la falta de fuentes de información y criterios objetivos para el análisis y evaluación de la investigación y en especial de la acalidad" de sus resultados. La situación es extrema en humanidades, pero distintas ramas de las ciencias sociales, la ingeniería, las ciencias de la salud e incluso las experimentales también tienen ese problema. En todos estos casos la referencia al SCI no resuelve el problema.

\subsubsection{Estructura}

Incremento de las relaciones Universidad-Empresa

Se constata un aumento de las relaciones con el ámbito empresarial, que parece ser un fenómeno bastante generalizado, aunque se sigue percibiendo como insuficiente en la mayoría de los casos. Si bien en la mayoría de los informes se considera insuficiente el nivel alcanzado en este punto.

Incremento de la madurez de los grupos de investigación

Se valora positivamente el aumento de madurez de los grupos de investigación, entendiendo ésta como estabilidad en personal y líneas de investigación.

Mejora de la gestión de los procesos de investigación

Se considera que ha mejorado notablemente la gestión de la investigación: información, transferencia de resultados, tanto en las instituciones estatales como en los propios servicios de las Universidades.

En cualquier caso existe bastante coincidencia en señalar la poca colaboración y comunicación interna entre los investigadores de un mismo departamento, incluso dentro de los límites de la misma área de conocimiento o especialidad científica.
Disfuncionalidad de la plantilla docente

En bastantes casos en los informes de evaluación se señala como un dato negativo la baja proporción de doctores en el personal investigador y el exceso de profesores asociados.

En la misma dirección, abundan las quejas por el exceso de carga docente, agravado por el tránsito a los nuevos planes de estudio. Finalmente, la carencia de objetivos estratégicos dificulta la planificación de la plantilla de personal investigador.

\subsubsection{Resultados}

Se valora positivamente el aumento de la producción y de la calidad de los resultados de investigación y su mayor proyección internacional, que se concreta en la participación en programas europeos, ponencias en congresos, etc.

\subsection{La organización universitaria}

Existe una acusada disfuncionalidad en los procesos de planificación, organización y gestión de la tilulaciones dado que, aunque inicialmente constituye una responsabilidad atribuida a los Centros, está condicionada por decisiones que toman los Departamentos. De acuerdo con la normativa vigente, las políticas relativas al profesorado dependen de los Departamentos, circunstancia que condiciona los procesos de planificación y gestión de las enseñanzas específicas de una titulación que llevan a cabo los Centros. La falta de coordinación entre ambos órganos (Departamentos y Centros) constituye una de las principales dificultades que actúa en detrimento de la calidad de las enseñanzas.

Esta organización bicéfala de las titulaciones constituye una de las principales debilidades que condicionan la calidad en la gestión de los procesos de enseñanza y se pone de manifiesto de forma patente a la hora de formular las quejas y reclamaciones que se generan en el ámbito académico. Aunque administrativamente se deben formular en el Centro, dado que la mayoría de ellas implican de algún modo al profesorado, el Decano o Director del mismo se ve obligado a trasladar el expediente al Departamento tanto para solicitar la información necesaria como para arbitrar la solución oportuna.

La ausencia de un único Órgano con competencia y responsabilidad sobre la gestión y los resultados de una titulación, o la debilidad del funcionamiento de los órganos colegiados no sólo ha impedido la creación de una cultura docente específica sino que tampoco ha estimulado la colaboración y trabajo en equipo entre el profesorado. La actividad docente es considerada como una cuestión individual de cada profesor sin tener en cuenta que la calidad de las enseñanzas exige un proyecto colectivo y 
la coordinación de todos los docentes tanto a nivel de objetivos como de procedimientos.

Igualmente se constata que las instituciones no han establecido mecanismos para generar una cultura específica sobre la enseñanza universitaria como prestación de un servicio a la sociedad con el fin de que el profesorado tomara conciencia de. que su función docente exige coordinación y trabajo en equipo. El desarrollo, únicamente, de sistemas de evaluación del profesorado basados sobre encuestas de opinión a los estudiantes ha contribuido a reforzar la cultura de la individualidad frente a una concepción de la calidad de las enseñanzas como reto y exigencia institucional.

Esta falta de coordinación y reflexión colectiva sobre los procesos de docencia relativos a una titulación se pone de manifiesto de forma patente en los informes realizados por las Universidades. En las valoraciones realizadas por los distintos Comités a la hora de estimar los factores que condicionan la calidad de las enseñanzas se tiende a resaltar más aquellos aspectos de la institución que dependen del sistema educativo que los relativos a las competencias derivadas de la autonomía universitaria. De ahí que, aunque los informes tienden a ser predominantemente descriptivos, cuando se llegan a formular juicios de valor normalmente los-procesos de atribución se efectúan utilizando criterios externos.

\section{Inexistencia de planes de calidad}

Existe una notable heterogeneidad entre los niveles de gestión de las Universidades. En algunas Universidades existen planes de calidad. En otras, existen planes generales para toda la Universidad, pero que o son muy efectivos o no son sentidos como tales por los autores de los autoinformes.

Por otra parte, salvo en algún caso, no existen estudios sobre satisfacción del cliente.

\section{Fragmentación del proceso de decisión}

El exceso de comisiones para la toma de decisiones es señalado sistemáticamente como un problema para la gestión eficiente. En muchas Universidades la gestión está diluida en manos de multitud de comisiones dentro de cada titulación. Aunque en algunas la gestión está por el contrario concentrada en pocas manos con gran capacidad decisoria.

En este mismo sentido, las relaciones para la gestión de las titulaciones son consideradas complejas y se señala falta de coordinación entre departamentos para la gestión de la titulación. La coordinación interdepartamental para la gestión de la titulación patece escasa.

\section{Ineficiencia de los sistemas de información}

Se valora muy negativamente el deficiente aprovechamiento de la información disponible, y como consecuencia, la incorrecta gestión de la información y la carencia de indicadores objetivos que permitan situar el estado de cosas en cada momento.

\section{Deficiencias en la gestión de personal}

Varios informes de evaluación indican deficiencias en la gestión de personal, entre las que cabe señalar.

1. Las dificultades de promoción, la carencia de plantillas teóricas o la inadecuación de éstas cuando existen, es resaltada por muchos informes.

2. La falta de formación docente del profesorado y de cursos de renovación pedagógica es citado frecuentemente como un problema serio, así como la escasa utilización de las nuevas tecnologías en la enseñanza.

3. Un aspecto que es resaltado como motivo de muchas dificultades es la falta de flexibilidad y movilidad del profesorado.

4. En general, la existencia de escaso personal de servicios, especialmente de ayuda a la investigación es señalado por una buena parte de los informes.

5. Igualmente, la carencia de formación para el PAS adecuada para los puestos que desempeñan y-la falta de manuales de gestión que regulen los procesos, son también señalados como una carencia importante.

\section{Rendimiento adecuado de la plantilla de personal y servicios}

Generalmente en los informes de evaluación se resalta el buen nivel de cumplimiento de las obligaciones laborales de profesores y personal de administración y servicios. Y se subraya el clima cordial de relaciones laborales.

\section{Calidad de los procesos administrativos}

De acuerdo con la mayoría de los informes de evaluación los procesos básicos de gestión administrativa, como por ejemplo la matricula o la gestión de nóminas, por citar sólo dos ejemplos, funcionan con suficiente eficacia y eficiencia. 


\section{Propuestas para mejorar la calidad}

En este capitulo se recogen las principales propuestas para mejorar la calidad señalalas en los Informes realizados por las Universidades que evaluaron algunas de sus Titulaciones en la primera convocatoria (OM de 21 de febrero de 1996) del Plan Nacional de Evaluación de la Calidad de las Universidades (R.D. de 1 de diciembre de 1995). Se resumen propuestas de actuación en relación con la enseñanza, la investigación y la organización universitaria, tanto en el ámbito de la Universidad (unidad evaluada) como en el de las administraciones educativas o en el del Consejo de Universidades.

Con carácter general, las propuestas para mejorar la calidad que figuran en los informes de evaluación señalan una carencia en la financiación y en los recursos humanos y materiales que moviliza el sistema universitario, al tiempo que subrayan que el proceso de evaluación permite promover una orientación en la asignación de recursos vinculada a incrementos en la eficacia y en la eficiencia de la Universidad.

\subsection{Propuestas para mejorar los procesos de enseñanza}

Las propuestas para mejorar los procesos de enseñanza pueden resumirse en la siguiente lista:

\subsubsection{Medidas intermas de la Universidad}

Identificar los objetivos de la titulación

Una de las debilidades más significativas puestas de manifiesto en la mayor parte de los informes de evaluación se refiere a la falta de concreción y formalización de las metas y objetivos de cada enseñanza.

En los informes de evaluación se señala que identificar con precisión, en el ámbito de la Universidad, la finalidad de cada titulación es un requisito básico para orientar el programa docente de tal forma que pudiera cumplir los propósitos que de forma explícita quiera desarrollar cada Universidad; para ello en los informes de evaluación se proponen las siguientes acciones:

1. Definir las metas y objetivos concretos de cada titulación en función tanto de las expectativas y demandas educativas, sociales. económicas o políticas, como de las ventajas competitivas de la institución.
2. Identificar los perfiles profesionales y académicos vinculados con las titulaciones a fin de precisar las competencias sociales y laborales que orientan el proceso formativo. Para ello parece imprescindible desarrollar instrumentos de vinculación de las instituciones universitarias con sus egresados y en general con los sectores económicos directa o indirectamente relacionados con cada enseñanza.

\section{Establecer un Plan Estratégico}

Un segunda inconsistencia que se señala igualmente en la mayoría de los informes de evaluación deriva de la inexistencia de planes estratégicos que permitieran asegurar la eficacia del proceso de enseñanza, cumplir los objetivos de cada titulación, en términos de eficiencia. Por ello en un amplio número de informes de evaluación se propone que cada Universidad elabore un plan estratégico en el que se contemplen los objetivos a alcanzar a corto y medio plazo en cada titulación así como los recursos y estrategias necesarios para llevar a cabo las actividades que de él se deriven. El Plan estratégico, entre otras, deberá tener en cuenta las siguientes actuaciones:

1. Incorporar sistemas de coordinación de las actividades académicas que se desarrollan en el ámbito de una titulación a fin de lograr la máxima coherencia y adecuación tanto en los contenidos impartidos como en las estrategias docentes utilizadas o en los procedimientos de evaluación del aprendizaje de los alumnos, que deberán contar con criterios objetivos expresos y referirse al rendimiento global.

2. Establecer sistemas de control y autorregulación de la docencia, que tengan en cuenta que la calidad de una titulación depende fundamentalmente de acciones y decisiones institucionales, por lo que una orientación centrada, como hasta ahora, exclusivamente en la actuación y evaluación individual de cada profesor parece claramente insuficiente.

3. Establecer cauces y mecanismos sistemáticos de análisis del progreso académico de los alumnos a lo largo de los estudios, y de los resultados obtenidos en el período temporal establecido en los planes, valorando las causas y factores que inciden sobre las tasas de éxito y fracaso.

4. Potenciar la función tutorial del profesor creando cauces y estímulos que permitan que el alumno haga una mayor utilización de la misma como estrategia de aprendizaje. A este respecto se considera importante crear la figura del profesor-tutor para cada alumno a lo largo de la carrera.

5. Intensificar las aetividades relativas a la dimensión práctica del currículum mediante la dotación de los recursos 
necesarios así como vincular el desarrollo de estas actividades al mundo laboral.

6. Establecer con carácter normativo la elaboración de Guías didácticas para cada titulación con el fin de informar a los alumnos sobre los criterios y procedimientos que orientan las actividades de enseñanza y aprendizaje de los estudios que realiza.

7. Potenciar cauces de orientación e información a los estudiantes sobre las demandas del mundo laboral y profesional vinculadas a las diversas titulaciones y desarrollar su relación con los organismos y servicios que gestionan ofertas de empleo.

Racionalizar los planes de estudio

Sin perjuicio de su necesaria integración en el plan estratégico, un tercer aspecto especialmente relevante hace referencia a las disfuncionalidades observadas en los planes de estudio aprobados por cada Universidad, por ello en los informes de evaluación se propone racionalizar la ordenación y estructuración de los planes de estudios a fin de corregir las principales deficiencias detectadas relacionadas con el número de asignaturas y horas de clase, con la organización de itinerarios, la fragmentación de las asignaturas, la escasa optatividad real para el alumno, o la reducida dimensión práctica del currículum, etc.

\subsubsection{Medidas de carácter general}

Muchas de las cuestiones señaladas en el ámbito de la Universidad, como el caso de los planes de estudio, requieren acciones generales que desde el ámbito de las Administraciones educativas o desde el Consejo de Universidades impulsen su desarrollo.

Junto a ello en los informes de evaluación se señalan otras cuestiones que se sitúan específicamente en un ámbito global, entre ellas pueden destacarse las siguientes:

1. Incrementar los recursos del sistema universitario, modificando el modelo de asignación, de acuerdo con las orientaciones previstas en el Informe de Financiación aprobado por el Consejo de Universidades en 1994.

2. Promover una cultura sobre la función docente como un servicio social que exige a las instituciones y al profesorado plantear, enfocar y adaptar su trabajo desde la perspectiva de las necesidades sociales al margen de sus intereses académicos personales.

3. Establecer un sistema de formación pedagógica del profesorado antes de comenzar a ejercer la función docente y que actúe de ayuda y perfeccionamiento didáctico a lo largo de su carrera.

4. Revisar los sistemas de acceso a los diversos estudios con el fin de que la selección de los alumnos no se efectúe únicamente con criterios generales.

5. Promover políticas de racionalización y promoción de los recursos humanos vinculados a una titulación que no sólo posibiliten la selección de buenos profesores sino que también potencien su función docente.

6. Establecer mecanismos de seguimiento de los graduados en su proceso de inserción profesional que no sólo nos informe sobre las expectativas del mercado de trabajo sino que también actúe como realimentación de los perfiles académicos y profesionales de las titulaciones.

7. Generar políticas de racionalización de los recursos materiales y humanos disponibles a fin de evitar las ineficiencias y disfuncionalidades observadas.

8. Intensificar los convenios e intercambios de la titulación con el contexto social y laboral próximo a fin de lograr una mayor proyección y vinculación de la institución universitaria con la sociedad.

\subsection{Propuestas para mejorar la investigación}

En los informes de evaluación se desgranan muchas propuesta encaminadas a resolver los problemas detectados y a mejorar la situación que se ha evaluado. Como nota general cabe señalar que existe una tendencia bastante acusada a situar la solución de los problemas no en el nivel en el que se produce la evaluación sino en los niveles superiores de toma de decisiones (rectorado, gobiemo, etc.). Aunque en ocasiones esta estrategia es el resultado de factores objetivos (escasa capacidad de maniobra a nivel departarnental, etc.), en otras muchas revela también cierto fracaso en la correcta orientación del proceso de autoevaluación.

Las propuestas más comunes y relevantes se pueden resumir en la siguiente lista:

\subsubsection{Medidas internas del Departamento}

1. Promover la concentración de investigadores en proyectos comunes de la mayor entidad posible.

2. Incentivar la definición explícita de los objetivos y la programación de la investigación en períodos anuales 0 plurianuales. 


\subsubsection{Medidas internas de la Universidad}

1. Mayor dedicación de recursos internos a promover investigación.

2. Mejorar los criterios (objetivos) de distribución interna de fondos.

3. Promover las relaciones internas y la investigación multidiscipiinar.

4. Potenciar e incentivar la investigación de calidad, diseñando mecanismos de competencia y de reconocimiento de la calidad.

5. Potenciar e incentivar la renovación e innovación en las líneas de investigación.

\subsubsection{Medidas generales}

1. Debería pensarse en adoptar medidas que animen a las Universidades a adoptar planes estratégicos de desarrollo de la investigación en sus departamentos, superando la actitud más bien pasiva que actualmente predomina en las Universidades, acostumbradas a que las iniciativas en el desarrollo de la investigación provienen de instancias externas, como la CICYT, etc.

2. Incrementar el personal de alta cualificación en gestión, el personal de apoyo de administración y el número de técnicos auxiliares.

3. Establecer criterios objetivos de evaluación de los resultados científicos a nivel institucional, especialmente en áreas de ciencias sociales y humanas y en áreas de ingeniería.

\subsection{Propuestas para mejorar la organización universitaria}

\subsubsection{Medidas internas de la Universidad}

1. Creación de un Órgano responsable directo de la gestión y de los resultados de cada Titulación con capacidad de decisión efectiva sobre todos los aspectos didácticos y organizativos de cada enseñanza.

2. Establecer planes de calidad que incluyan directrices en la gestión ordinaria de todos los procesos universitarios.

3. Establecer políticas de recursos humanos, tanto para profesorado como para personal de servicios que definan puestos y criterios de promoción.

\subsubsection{Medidas de carácter general}

Una actuacion estratégica, de la que dependen gran parte de las oportunidades de incrementar la calidad de ios procesos de toma de decisión en todos los niveles del sistema universitario, se refiere a la necesidad de mejorar sensiblemente los sistemas de información estadística a disposición de la Universidad española, sobre todo en lo relativo a la rapidez con la que deben publicarse los principales resultados.

Las actuación que viene desarrollando la Secretaría General del Consejo para la normalización y depuracion necesarias para consolidar la información facilitada por las Universidades, abre la posibilidad de contar, al final de cada año académico, con los datos requeridos por el conjunto de los actores del sistema universitario.

\section{Propuestas para mejorar el Plan Nacional de Evaluación}

En este capitulo se señalan las propuestas que figuran en los informes de evaluación elaborados por las Universidades y otras de carácter general entre las que destacan la necesidad de contar con un instrumento de diagnóstico rápido y suficientemente preciso de la calidad del conjunto del sistema universitario y de reformular el papel de las Comunidades Autónomas en el desarrollo del Plan Nacional de Evaluación.

Con carácter general, el método de evaluación desarrollado en el Plan Nacional permite atender fielmente los objetivos del Plan Nacional que se refieren a la promoción de la evaluación institucional y dotar a las Universidades y a las administraciones educativas de un método homogéneo y común para el desarrollo de los procesos de evaluación para la mejora de las Universidades.

Por lo que respecta a los objetivos del Plan que persiguen proporcionar al entorno inmediato de cada Universidad información relevante sobre la calidad de su Universidad y a las administraciones educativas de las Comunidades Autónomas información objetiva sobre la calidad alcanzada por las Universidades de su competencia, el método de evaluación parece suficientemente adecuado.

Sin embargo, en relación con los objetivos que propugnan proporcionar al conjunto de la sociedad española información relevante y objetiva sobre la calidad de las Universidades y al Ministerio de Educación y Cultura y al Consejo de Universida- 
des información igualmente objetiva sobre el nivel de calidad alcanzado por el conjunto del sistema universitario el método establecido en la convocatoria de 1996, desarrollado en la guía de evaluación no parece suficientemente idóneo.

Esta debilidad del método de evaluación deriva sobre todo de la falta de indicadores de rendimiento como criterios de calidad, por lo que es necesario acordar por el conjunto dél sistema universitario el alcance y la introducción progresiva de significativos indicadores de ejecución que eviten la falta de precisión en las valoraciones internas y externas, especialmente en los ámbitos de la enseñanza y de la gestión.

Por otro lado, el sistema universitario requiere ofrecer a la sociedad un diagnóstico rápido y suficientemente preciso de la calidad del conjunto del sistema, para ello, podría estudiarse incorporar en el Plan Nacional una orientación que permitiera realizar una comprobación inmediata de los principales elementos que conforman la estructura, los procesos y los resultados del sistema, a través de una muestra representativa de las distintas titulaciones, departamentos y servicios de la Universidad.

Esta propuesta puede garantizar que anualmente, al finalizar el curso lectivo, la Secretaría General del Consejo de Universidades elabore una radiografía de conjunto sobre la calidad de la Universidad.

\section{Organización y gestión del proceso de evaluación}

En primer término, parece necesario formular de nuevo la participación de las administraciones educativas de las Comunidades Autónomas en el Plan de Evaluación, de forma que puedan adoptar un protagonismo decisivo en el desarrollo del Plan, mientras que las actividades del Consejo de Universidades se orienten a asegurar la coordinación y la suficiente homogeneidad de los procedimientos de evaluación, así como la acreditación de los miembros de los comités de evaluación externos.

Igualmente es conveniente fortalecer la estructura organizativa de la Secretaría General del Consejo, constituyendo la Oficina de gestión de evaluación prevista en el Plan Nacional y dotando a la Secretaría General de los medios humanos y materiales que señala el Decreto 1947/95, de 1 de diciembre.

\section{Requisitos previos al inicio de la evaluación institucional}

No es eficaz ni eficiente que la fase de revisión interna (autoevaluación) se oriente a la obtención de los datos necesarios para valorar la calidad. Tal como se ha señalado, es imprescindible dotar al sistema universitario de un perfil de estadística y datos de gestión que permita la comunicación entre sus diferentes actores.

Por otro lado, es aconsejable extender las acciones encaminadas a divulgar la cultura de la evaluación que permitan crear un clima propicio que permita que el desarrollo del Plan Nacional sea efectivamente una estrategia orientada a mejorar la calidad.

\section{Simplificación y adecuación de la guia de evaluación}

Con carácter general, la guía de evaluación debe simplificarse y en especial adaptarse a las singularidades específicas de las grandes áreas disciplinares, al tiempo que es necesario establecer fórmulas para reducir la complejidad organizativa y lós costes del proceso de evaluación. En particular pueden considerarse los siguientes aspectos:

1. Es muy importante que se defina claramente la articulación de la evaluación de la investigación con el resto del proceso de la evaluación institucional, especialmente con la evaluación de la enseñanza, aclarando las relaciones entre los diversos niveles y unidades de evaluación.

2. También es relevante enfatizar lá necesidad de adoptar una perspectiva específica en la evaluación institucional, no reducible, especialmente, a la evaluación individual de los investigadores.

3. Con carácter urgente, para la continuidad del Plan, debería resolverse la carencia actual de criterios objetivos de evaluación de calidad de las publicaciones científicas, especialmente en el campo de las humanidades y las ciencias sociales.

4. Mejora de los protocolos relativos a la organización universitaria enfocándolos hacia la crítica y el análisis de los procesos de gestión y de toma de decisiones, y no a la enumeración de situaciones o al listado de datos estadísticos.

5. Facilitar mediante los correspondientes cambios en la Guía la realización de evaluaciones de todos los servicios y procesos de decisión. 


\section{Ânerso If}

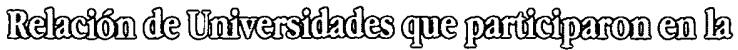

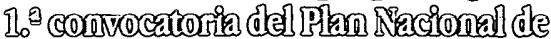

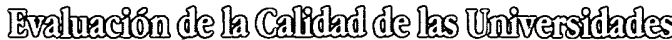

\begin{tabular}{|l|l|}
\hline Alcalá de Henares & león \\
\hline Alicante & Leida \\
\hline Almeŕa & Málaga \\
\hline Antonio de Nebrija & Murcia \\
\hline Autónoma de Madrid & Oberta de Catalunya \\
\hline Autónoma de Barcelona & Oviedo \\
\hline Barcelona & País Vasco \\
\hline Burgos & Politécnica de Catalunya \\
\hline Cádiz & Politécnica de Madrid \\
\hline Cantabria & Politécnica de Valencia \\
\hline Carlos III & Pompeu Fabra \\
\hline Castilla-La Mancha & Pontificia de Salamanca \\
\hline Complutense & Pública de Navarra \\
\hline Córdoba & Ramón Llull \\
\hline Europea de Madrid (CESES) & Rovira Virgili \\
\hline Extremadura & Salamanca \\
\hline Girona & San Pablo - CEU \\
\hline Granada & Santiago \\
\hline Huelva & Sevilla \\
\hline Islas Baleares & UNED \\
\hline Jaén & Valencia \\
\hline Jaume I & Valladolid \\
\hline La Laguna & Zaragoza \\
\hline Las Palmas & \\
\hline & \\
\hline
\end{tabular}

Angerar III

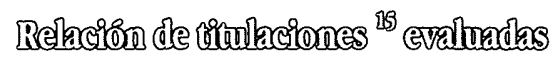

\begin{tabular}{|l|l|}
\hline \multicolumn{1}{|c|}{ UNIVERSDDAD } & \multicolumn{1}{c|}{ TITULACIÓN } \\
\hline Alcalá de Henares & Biología \\
\hline Alicante & $\begin{array}{l}\text { Optica } \\
\text { Química }\end{array}$ \\
\hline Almería & $\begin{array}{l}\text { CC. Ambientales } \\
\text { Química }\end{array}$ \\
\hline Antonio de Nebrija & $\begin{array}{l}\text { I. de Gestión } \\
\text { I. de Sistemas } \\
\text { I. Informático }\end{array}$ \\
\hline Autónoma de Madrid & $\begin{array}{l}\text { A. de Empresas } \\
\text { Economía } \\
\text { Geografia }\end{array}$ \\
\hline
\end{tabular}

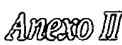

\begin{tabular}{|c|c|}
\hline \multicolumn{2}{|c|}{ 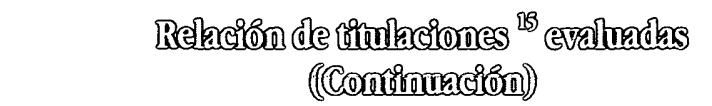 } \\
\hline UNIVERSIDAD & TITULACIÓN \\
\hline Autónoma de Madrid ${ }^{1}$ (cont.) & $\begin{array}{l}\text { I. Informático } \\
\text { Psicología }\end{array}$ \\
\hline Autónoma de Barcelona ${ }^{1}$ & $\begin{array}{l}\text { C. Audiovisual } \\
\text { Empresariales } \\
\text { I. de Gestión } \\
\text { I. de Sistemas } \\
\text { I. Informático } \\
\text { Maestro E. Primaria } \\
\text { Políticas } \\
\text { Relaciones Laborales }\end{array}$ \\
\hline Barcelona $^{1}$ & $\begin{array}{l}\text { Biología } \\
\text { Bioquímica } \\
\text { Empresariales } \\
\text { Empresariales, Vic. } \\
\text { Farmacia } \\
\text { I. Electrónico } \\
\text { I. Químico }\end{array}$ \\
\hline Burgos & C. Tecnología Alimentos \\
\hline Cádiz & Química \\
\hline \multicolumn{2}{|l|}{ Cantabria $^{2}$} \\
\hline Oviedo & $\begin{array}{l}\text { Física } \\
\text { I. Químico o } \\
\text { Matemáticas } \\
\text { Química }\end{array}$ \\
\hline País Vasco ${ }^{1}$ & $\begin{array}{l}\text { C.T. Alimentos } \\
\text { Diet. y Alimentación } \\
\text { I. Industrial ( } 2 \text { centros) } \\
\text { Topografia } \\
\text { I. Químico } \\
\text { Química } \\
\end{array}$ \\
\hline Politécnica de Catalunya $^{1}$ & $\begin{array}{l}\text { I. Electrónica } \\
\text { I. Gestión ( } 3 \text { centros) } \\
\text { I. Sistemas } \\
\text { I. Telecomunicación } \\
\text { I. Automática } \\
\text { I. Industrial } \\
\text { I. Informático } \\
\text { I.T. Telecomunicación }\end{array}$ \\
\hline Politécnica de Madrid & $\begin{array}{l}\text { I. Gestión } \\
\text { I. Sistemas } \\
\text { I. Telecomunicación }\end{array}$ \\
\hline Politécnica de Valencia & $\begin{array}{l}\text { I. Gestión } \\
\text { I. Sistemass } \\
\text { I. Informática } \\
\text { L. Informática } \\
\text { Diseño Industrial } \\
\text { I. Electricidad } \\
\text { I. Electrónica } \\
\text { I. Mećnica } \\
\text { Química Industrial }\end{array}$ \\
\hline
\end{tabular}




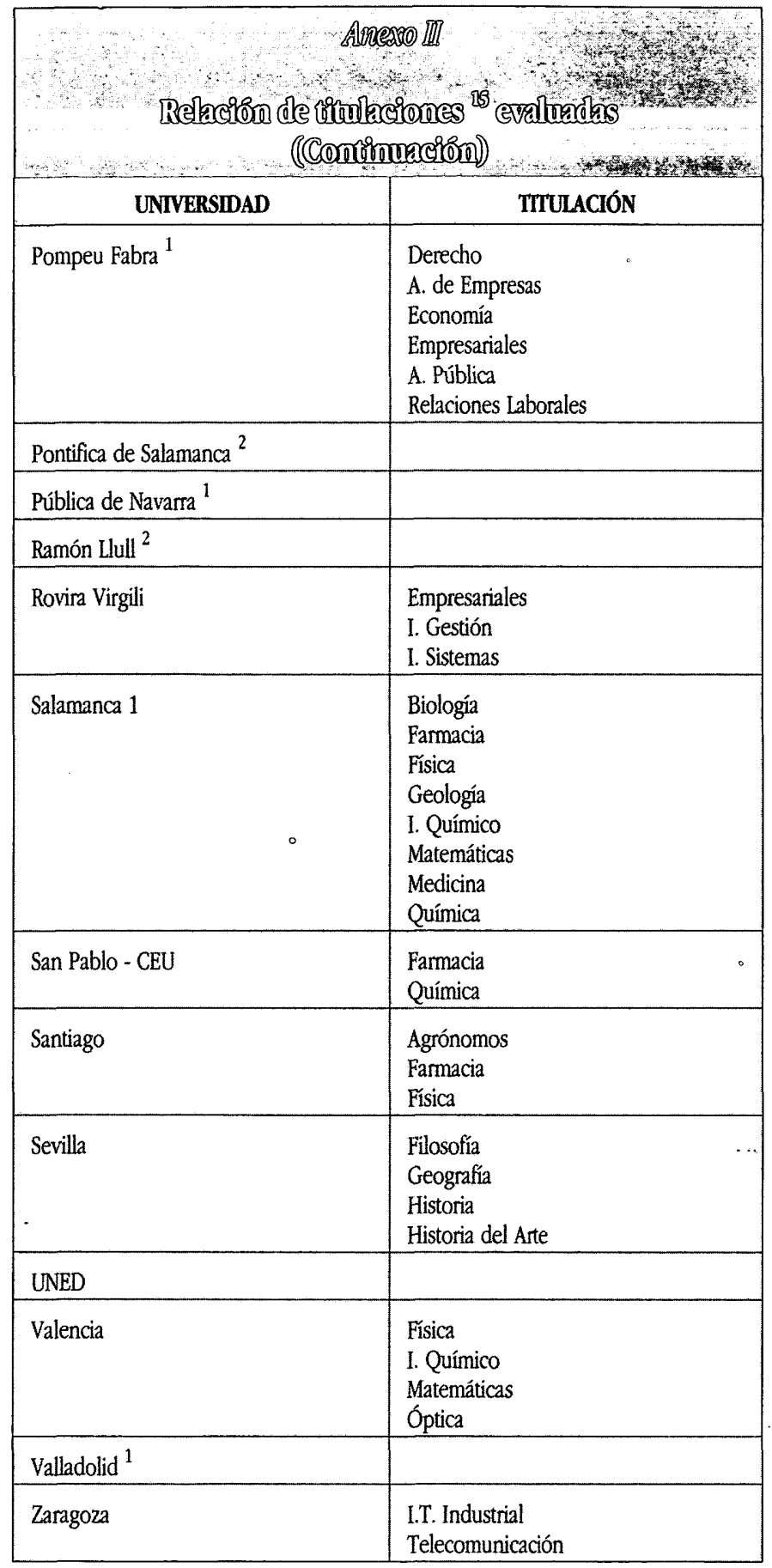

1 Proyecto global.

2 Acción especial.

1 Programa de Evaluación Institucional de la Calidad de las Universidades. Acuerdo del Pleno del Consejo de Universidades de 25 de septiembre de 1995.

2 Real Decreto 1947/1995, de 1 de diciembre, por el que se establece el Plan Nacional de Evaluación de la Calidad de las Universidades (BOE núm. 294 de 9 de diciembre de 1995).

${ }^{3}$ Acuerdo por el que se propone al Ministro de Educación las características y condiciones de la primera convocatoria del Plan Nacional de Evaluación. Acuerdo del Pleno del Consejo de Universidades de 14 de diciembre de 1995.
${ }^{4}$ Orden de 21 de febrero de 1996 de convocatoria para el año 1996 del Plan Nacional de Evaluación de la Calidad de las Universidades (BOE núm. 51 de 28 de febrero de 1996).

5 Segunda sesión del Comité Técnico celebrada el 24 de mayo de 1996.

${ }^{6}$ Orden de 30 de octubre de 1996 por la que se resuelve la concesión de financiación para proyectos de evaluación presentados en el Plan Nacional de Evaluación de la Calidad de las Universidades (BOE núm. 270 de 8 de noviembre de 1996). 
- El contenido de este Informe sólo se réiere a los aspectos realizados con referencia al 8 de noviembre de 1997.

${ }^{3}$ Por acuerdo del Pleno del Consejo de Universidades en sesión celebrada en Alicante el 4 de julio de 1996, la Comisión Ejecutiva del Plan, presidida por el Secretario de Estado de Univiversidades, Investigación y Desañollo, está compuesta por los Consejeros de todas las Comunidades Autónomas con competencia en materia de educación universitaria, por los Vicepresidentes de la Comisión de Coordinación y Planificación y de la Académica, por los miembros de la Mesa del Pleno del Consejo de Universidades elegidos por las Comunidades Autónomas y por las Universidades, por los poravoces de las cuatro Subcomisiones de Evaluación de Humanidades, Ciencias Experimentales y de la Salud, Ciencias Sociales y Junídicas, Técnicas y Alumnado. Centros y Normativa General del Consejo de Universidades, por el Director General de Enseñanza Superior del Ministerio de Educación y Cultura y por el Secretario General del Consejo de Universidades.

9 El Pleno del Consejo de Universidades acordó en Cádiz, en septiembre de 1992, desarrollar un Programa Experimental de Evaluación de la Calidad del Sistema Universitario. Los resultados del Programa Experimental pueden verse en el documento n. 13 Informe final elaborado por el Comité Técnico de la Secretaría General del Consejo de Universidades en julio de 1994 y que fue debatido en el encuentro sobre Evaluación de las Universidades en España, celebrado en la Universidad Internacional Menéndez Pelayo en septiembre de 1994.

${ }^{10}$ El Proyecto Piloto Europeo se desarrolló entre 1994 y 1995. Sus resultados se presentaron en la Conferencia Final celebrada en la Universidad de Las Palmas de Gran Canaria, en diciembre de 1995.

11 Recomendación de la Comisión de la Unión Europea al Consejo relativa a la cooperación europea en materia de garantía de la calidad en la enseñanza superior. Mayo 1997.

12 El acuerdo de 25 de septiembre del Pleno del Consejo de Universidades en el que se establece el Plan Nacional de Evaluación determina que el Comité Técnico será presidido por el Secretario General del Consejo de Universidades y estará formado' por expertos en evaluación de la enseñanza, la investigación y de la gestión universitaria, nombrados por la Presidenta del Consejo. Serán miembros natos del Comité Técnico el Director General del Ministerio de Educación y Cultura con competencias en materia de enseñanza universitaria, que actuará de Vicepresidente del Comité Técnico, el Director de la Agencia Nacional de Evaluación y Prospectiva, y el Vicesecretario del Consejo de Universidaaes del que dependa la Oficina de Gestión de Evaluación.

Por Orden de 13 de marzo de 1996 (BOE núm. 68 de 19 de marzo) el Ministro de Educación designó miembros del Comité Técnico del Plan Nacional de Evaluación de la Calidad de las Universidades a los siguientes expertos: D. Sebastián Rodríguez Es- pinar, Catedrático de Métodos de Investigación y Diagnóstico en Educación, de la Universidad de Barcelona; D. José Ginés Mora Ruiz, Profesor titular de Economía Aplicada de la Universidad de Valencia; D. Mario de Miguel Díaz, Catedrático de Métodos de Investigación y Diagnóstico en Educación, de la Universidad de Oviedo; D. Miguel Ángel Quintanilla Fisac. Catedrático de lógica y Filosofía de la Ciencia, de la Universidad de Salamanca; D. Francisco Pérez García, Catedrático de Fundamentos del Análisis Económico, de la Universidad de Valencia; D. Lluis Jofre Roca, Catedrático de Teoría de la Señal y Comunicaciones, de la Universidad de Catalunya; D. Miguel Valcárcel Cases, Catedrático de Química Analítica, de la Universidad de Córdoba.

${ }^{13}$ Se señalan a continuación las fechas y los acuerdos más importantes de cada una de las sesiones plenarias del Comité Técnico.

La sesión constitutiva se celebró el 15 de marzo de 1996 y acordó aprobar el calendario de trabajo y la constitución de cuatro grupos de trabajo. Uno de ellos, de carácter permanente, formado por D. Sebastián Rodríguez Espinar, D. Mario de Miguel Díaz, D. José Ginés Mora, asistidos por el Vicesecretario de Estudios del Consejo de Universidades.

La segunda sesión se celebró el 24 de mayo de 1996, y se acordó proponer al Secretario General del Consejo la financiación de los proyectos presentados en la convocatoria de 1996.

La tercera sesión se celebró el 18 de junio de 1996, y se aprobó la Guía de la Evaluación y el programa de formación de los comités de evaluación externos e internos.

La cuarta sesión se celebró el 4 de septiembre de 1996 y se acordaron los criterios para la selección de los miembros de los comités de evaluación externos.

En la quinta sesión, celebrada el 23 de enero de 1997, se debatió un borrador de la convocatoria para 1997 del Plan Nacional de Evaluación y el contenido de la guía de los evaluadores externos.

En la sexta sesión, celebrada el 10 de abril de 1997 , se seleccionaron los miembros de los comités de evaluación externa.

En la séptima sesión, celebrada el 7 de octubre de 1997, se debatieron las características del informe anual del Plan Nacional de Evaluación.

14 Varias Universidades están concluyendo la redacción del informe final. Únicamenté la Universidad Politécnica de Cataluña, en octubre de 1997, remitió a la Secretaría General un borrador de informe final.

${ }^{15}$ En esta relación no se incluyen los Servicios que se han evaluado independientemente de las Titulaciones (Biblioteca de Salamanca, Politécnica de Valencia y Politécnica de Catalunya; Servicio de Alumnado y Centro de Transferencia de Tecnología de la Politécnica de Valencia. En el Informe, cuando se señalan 130 Titulaciones, se presentan agregados estos Servicios con la relación de Titulaciones evaluadas. 


\title{
REVISTA \\ DEL SENADO

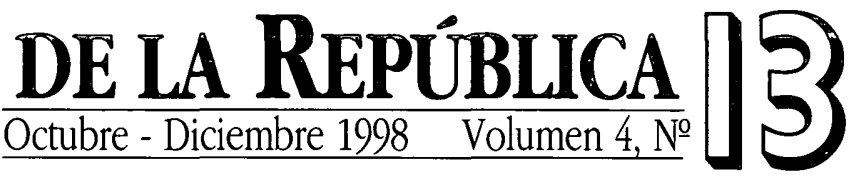

\section{Democracia y división de poderes}

\section{Posiciones}

María de los Ángeles Moreno, Enrique González Pedrero

y Alfredo Ling Altamirano

$\diamond$

Raúl González Schmal, Luis Raigosa Sotelo, Carlos San Juan Victoria,

Salvador Cárdenas Gutiérrez, Miguel Alejandro García Jaramillo, José Fernández Santillán, Sergio Zermeño, Elisur Arteaga Nava,

Lourdes Sayeg, Juan Romero y Emilio Zebadúa, Gerardo

Escutia García, Silverio Luján e Isidro H. Cisneros

$$
\diamond
$$

Debate

Eduardo Andrade, Edmundo González Llaca, Carlos Ímaz Gispert

y Ernesto Alvarado Ruiz

\author{
$\diamond$ \\ Crónica \\ Gustavo Mora y José Miguel Ramírez Cardena \\ $\diamond$ \\ Medalla de Honor Belisario Domingez \\ $\diamond$ \\ Entrevistas
}

Luis Mejía Guzmán, Eduardo Andrade y Auldárico Hernández

$\diamond$

Visitas de Estado

Juan Ramiro Robledo Ruiz y José Ramírez Gamero

Revista del Senado de la República

Gante, 4-1ํำ piso, Centro Histórico, México, D.F.

Tel. 7224800 ext. 6121, 6125 y 6132 